\title{
La expedición de esclavizados entre 1779 y 1783 según las notas de la Aduana de Buenos Aires y uno de los negocios que contienen
}

\section{The circulation of slaves between 1779 and 1783 according to the records of the Customs of Buenos Aires and one of the businesses that contain}

\footnotetext{
${ }^{1}$ Consejo Nacional de Investigaciones Científicas y Técnicas de Argentina, Buenos Aires, Argentina.
}

${ }^{2}$ Instituto de Estudios Historicos, Universidad Nacional de Tres de Febrero, Buenos Aires, Argentina.

*Correspondencia: fjumar@conicet.gov.ar

Resumen. A partir del análisis de las notas de aduana generadas en Buenos Aires se observan los esclavizados trasladados hacia el interior americano entre marzo de 1779 y diciembre de 1783 . Se cruzan informaciones con las de una de las operaciones que reflejan los datos a partir de documentación perteneciente a una firma mercantil porteña. Con ello, se espera proveer informaciones útiles a distintos fines al tiempo que se las relaciona con resultados previos de investigación.

Palabras clave: Río de La Plata; circuitos mercantiles; trata esclavista; siglo xviII.

CÓMO CITAR: Jumar, F. (2O21). La expedición de esclavizados entre 1779 y 1783 según las notas de la Aduana de Buenos Aires y uno de los negocios que contienen. América Latina en la Historia Económica, 28(1), 1-33. DOI: https://doi.org/10.18232/alhe.1027 
Abstract. From the analysis of the customs notes generated in Buenos Aires, the enslaved persons transferred to the American interior between March 1779 and December 1783 are observed. Information is crossed with those of one of the operations that reflect the data from documentation belonging to a Buenos Aires commercial firm. With this, it is expected to provide useful data for different purposes while relating them to previous research results.

Key words: Río de La Plata; trade circuits; slave trade; 18th Century.

JEL: N36; N96; O54.

Recibido: 28 de octubre de 2019

Aceptado: 24 de febrero de 2020

Publicado: 17 de diciembre de 2020.

Agradecimiento: Agradezco a los comentarios recibidos, en especial a A. Borucki -quien además me transmitió datos y documentación que enriquecen el texto original-, y a los evaluadores para la publicación cuyas sugerencias me ayudaron a mejorar el texto. Una primera versión de este trabajo, con el mismo título, fue presentada en el VI Congreso Latinoamericano de Historia Económica. Simposio 40 Trata, Mercado y Economía Global: Nuevas Aproximaciones desde la Historia Económica, Santiago de Chile, julio de 2019.

\section{INTRODUCCIÓN}

De un conjunto de investigaciones sobre el comercio practicado en y desde el complejo portuario rioplatense entre fines del siglo XviI y fines del XviII, que en diversa medida abordan tanto la circulación hacia el interior americano como hacia ultramar, se desprende -entre otras- una hipótesis de trabajo que propone que de modo gradual, y desde el siglo xviI, cobra cada vez mayor importancia la ruta que vincula Río de la Plata con el Bajo Perú por tierra hasta Valparaíso (con la mediación cuyana) y de allí por agua hasta El Callao. Esta ruta, que desde el complejo portuario rioplatense partía hacia el Oeste, parece haber llegado a ser la más significativa para el comercio practicado en o desde Río de la Plata hacia el interior americano y se habría articulado en torno al comercio de esclavizados y de yerba mate al tiempo que dinamiza la economía de Cuyo con las demandas del tráfico y la posibilidad de dar salida a sus excedentes en el litoral ${ }_{[}^{1}$

Una de las investigaciones aludidas analiza en general la salida de bienes debidamente registrados en la Aduana de Buenos Aires desde que comienza sus actividades en marzo de 1779 y hasta diciembre de 1783 (Jumar, 2019b 2 y otra se concentra en la ruta mencionada (Sovarzo, 2019).

${ }^{1}$ Para una síntesis, véase Jumar (2019a). El análisis general de los datos para el periodo 1779-1783 está en Jumar (2019b) y el análisis de su representatividad en Jumar (en prensa). Sobre el conjunto mayor en el que se inscribe la circulación vista desde Río de la Plata en el periodo, véase Jumar (2018). Sobre el contexto bibliográfico en que se inserta el texto, véase Jumar (2014). Para el comercio ultramarino, entre 1714 y 1778, véase Jumar (2016c) y entre 1779 y 1796, véase Camarda (2015).

2 Las informaciones numéricas provienen de Registros de Aduana de Antiguo Régimen (en adelante RegAduAR), base de datos marzo de 1779 a diciembre de 1783 recopilada a partir de las notas de aduana registradas en la Aduana de Buenos Aires, Archivo General de la Nación, Argentina (en adelante AGN-A), XIII-14-9-1; 14-9-5; 33-11-2; 3311-3; 34-1-5; 34-2-1; 34-2-5; 34-3-1; 34-4-1; 34-4-2; 34-1-5 (RegAduAR, base 1779-1783). Sobre la fuente y su tratamiento, véase Jumar (en prensa). RegAduAR es una aplicación informática desarrollada por Fernando Jumar y Alejandro Zurdo para el procesamiento de la información contenida en fuentes fiscales relacionadas con la circulación mercantil en el mundo hispánico durante el Antiguo Régimen. La base de datos correspondiente a los años 1779-1783 fue generada en el equipo de investigación dirigido por F. Jumar entre los años 2009 y 2016 . La primera carga de datos fue realizada por Maximiliano Acebal (marzo de 1779); Nicolás Biangardi (abril a septiembre de 1782); Ricardo Bogosian (enero, febrero y septiembre de 1781); José Bozzo (octubre y noviembre de 1780; noviembre de 1781); María Claudia Errecart (agosto, septiembre y noviembre de 1779; febrero, abril, y diciembre de 1780; marzo a julio, 
En cuanto a la representatividad de los datos, sobre todo en función del comercio ilegal desde el punto de vista español, se aborda el problema desde la capacidad de consumo de las sociedades involucradas. Se concluye que dicho tráfico no puede tener las proporciones que habitualmente se le asignan y que tornarían ilusorios los análisis realizados desde la circulación legal. De este modo, los datos recabados no sólo servirían para observar el entramado de rutas y la composición de la oferta, sino también la intensidad ${ }^{3}$ y densidad de los flujos con las mismas prevenciones que se deben tomar para cualquier circuito mercantil anterior o posterior, en el mundo observado u otro, en el que desde los poderes constituidos se busca obtener recursos del comercio por la vía fiscal (Jumar, en prensa).

El periodo observado, 1779-1783, es una de las tantas coyunturas en las que la circulación mercantil se ve afectada por conflictos armados y que forman parte de los escenarios habituales que enfrentaban los actores involucrados en el comercio del mundo hispánico durante el Antiguo Régimen. En el caso particular de Río de la Plata, su condición de frontera, tanto con los pueblos originarios no conquistados como con el mundo luso, más el atractivo que presentaba como puerta trasera de acceso a los circuitos de los metales preciosos producidos en Sudamérica, derivaron en que el conflicto o su amenaza haya formado parte de la cotidianidad de los tratos 5 En los años 1779-1783 la circulación anudada en Río de la Plata se debió adaptar a dos perturbaciones: las rebeliones altoperuanas de 1780-1781 y los efectos de la intervención de la monarquía hispánica en la guerra de independencia de los dominios británicos en América del Norte, con mayor intensidad entre 1780 y $1782 \sqrt[6]{6}$ Ello a su vez está contenido dentro de un proceso más amplio dentro de la monarquía hispánica en el que desde la corona se busca reforzar un cambio institucional en dirección de la centralización y homogeneización de la dominación en el conjunto de los dominios europeos, americanos y asiáticos 7 En el caso de Río de la Plata, ello se traduce en la intensificación de cambios que desde los años de 1730 buscaban por la vía administrativa reducir los márgenes de autonomía local, que se intensifican desde 1776-1777 con la creación del virreinato del Río de la Plata. Esta intensificación a su vez debe ser observada en un contexto en el que cualquier conjunto de intenciones de largo alient ${ }^{8}$ se ve truncado por las variables de contexto general que derivan en que, más que plasmar esas intenciones, se actúe para dar respuesta a las sucesivas coyunturas críticas que terminan en el estallido de la monarquía hispánica en 1808-1810 y en el inicio de la formación de Estados-nación de sus despojos, incluido el español.

En tal contexto, el objetivo de este texto es simple, del conjunto de datos generados para el periodo 1779-1783, a partir de las notas de salida de la Aduana de Buenos Aires, presentar en detalle los de la circulación de esclavizados y los de una de las tantas transacciones que contienen

octubre y diciembre de 1781; enero, febrero, marzo, octubre, noviembre y diciembre de 1782; enero, abril y junio de 1783); María Luz Jardón (enero y marzo de 1780); Fernando Jumar (mayo, julio, agosto a diciembre de 1783); Roberto Querzoli (mayo a agosto de 1780; agosto de 1781; febrero y marzo de 1783); María Emilia Sandrín (abril de 1779; septiembre de 1780); José Sovarzo (mayo, junio, julio, octubre y diciembre de 1779). La verificación, depuración, homogeneización y categorización de los datos estuvo a cargo de F. Jumar.

3 Cantidad y frecuencia de los contactos entre mercados.

${ }^{4}$ Cantidad de bienes puestos en circulación.

${ }^{5}$ Véase esta característica en Sandrín (2016), explotada para abordar el tema de la corona y la navegación comercial como dinamizadoras de la economía regional al tiempo que el mundo del trabajo vinculado a la satisfacción de las demandas que se generaban.

6 Véase Jumar (en prensa, El periodo 1779-1783).

7 Al respecto, véanse Kraselsky (2019) y Vaccani (2019).

${ }^{8}$ Sobre las reformas borbónicas en la historiografía argentina, véase Jumar (2016d). 
relacionada con la ruta que hacia el Oeste ponía en contacto Río de la Plata con Chile y el Bajo Perú .9 Con ello me propongo presentar algunos datos y enriquecer preguntas relacionadas con el lugar de la ruta del Oeste para el comercio practicado en o desde el complejo portuario rioplatense hacia el interior americano. En el camino, se intenta una descripción detallada que las fuentes permiten con el cruzamiento y extracción de informaciones contenidas en Registros de Aduana de Antiguo Régimen (base de datos 1779-1783) (en adelante, RegAduAR), lo que tal vez aporte datos útiles a otras investigaciones. En síntesis, se trata ante todo de un trabajo de base.

Para el seguimiento de la trata en Río de la Plata en el periodo abordado se toma como marco general trabajos de Alex Borucki $(2011,2015,2016,2017)$, que a su vez contienen densos estados del arte sobre el problema y se remite a ellos a quienes se interesen en este tráfico tan particular.10 En su periodización de la trata, Borucki sostiene que los años observados (1779-1783) quedan dentro de un lapso (1777-1791) que puede ser entendido como de reacomodamientos del tráfico tras la expulsión de los portugueses de Colonia del Sacramento (Borucki, 2016, pp. 12-16) y mientras la corona española ensaya nuevas vías legales de aprovisionamiento (Borucki, 2017, p. 53).

Tal vez la función mediadora de Colonia en manos portuguesas ya languidecía en los años 1770, aunque sin que se cortara 11 En una correspondencia que se extiende entre 1768 y 1798 entre dos individuos, uno instalado en La Plata (Juan Antonio Ruiz Tagle) y el otro en Buenos Aires (Francisco de Prieto y Pulido), se muestra que el contrabando por la vía portuguesa hasta la expulsión (1777) estaba naturalizado y a diferencia de otros temas peligrosos, se lo aborda de modo abierto en la correspondencia firmada 2 (Jumar, 2016a). Entre los favores que el altoperuano le pide al porteño en diversos momentos está la compra de esclavizados, para él o terceros, enviándole instrucciones precisas. Por ejemplo, en algunas cartas de 1773 y 1774 es cuestión del pedido de una esclavizada y Ruiz Tagle no se conforma con cualquier cosa 13 A Prieto y Pulido le

\footnotetext{
${ }^{9}$ Las informaciones sobre la operación que se presenta provienen del seguimiento de la trayectoria de un castellano del norte, con vinculaciones familiares en La Coruña y radicado en Buenos Aires desde sus 21 años, en 1778 (Jumar, 2016b). Entre los papeles recabados se encuentra un subconjunto que permite ver con algún detalle un negocio de venta de esclavizados en 1783.

10 También se remite a Damiani (2018) para acceder a otro estado del arte sobre la trata, a Rebagliati (2014) para un análisis de las posturas historiográficas ante la esclavitud en Río de la Plata y a Crespi (2000) para una síntesis del marco institucional en que se efectuó la trata en Río de la Plata y de las fuentes disponibles para su estudio.

${ }^{11} \mathrm{Al}$ respecto, A. Borucki tuvo la gentileza de compartir la siguiente información: "Los reportes españoles del Real de San Carlos, que están en el Archivo General de la Nación, muestran que todavía están llegando barcos esclavistas hasta 1775. AGN-A, IX-7-9-6 Real de San Carlos, 1762-1768, reporta el arribo de dos barcos esclavistas, en 9 de octubre y 22 de diciembre de 1768. En AGN-A, IX-7-9-7, 1769-1770, informa la llegada de 80 esclavos en un barco, y otros 150 en otro. En AGN-A, 7-10-2 Real de San Carlos 1773-1775, hay más indicaciones de llegadas de esclavos a Colonia.”

12 Los temas espinosos se tratan en billetes sueltos que se enviaban dentro del pliego y que no llevan ni destinatario ni firma. No siempre se está ante interlocutores fieles que los destruirían tras leerlos y gracias a esos billetes es posible comprender mejor vagas alusiones a ciertos temas en la correspondencia formal, que sería la única que podría haber sobrevivido si se destruían - como se esperaba- los papeles comprometedores.

${ }^{13}$ Es interesante la justificación de por qué se prefieren bozales. "La Negrita que comprare, no sea de las que hayan vendido en esa ciudad sino enteramente bozal, pues cuando las Porteñas se deshacen y venden alguna de aquellas, es porque han reconocido su mal genio, flojera y otro algún grave defecto” Archivo Histórico de la Provincia de Buenos Aires, La Plata, Argentina (en adelante AHPBA), 3-1-6-19, Juan Antonio Ruiz Tagle a Francisco de Prieto y Pulido, La Plata, 11 de octubre de 1773. Finalmente, Ruiz Tagle debe ceder en sus pretensiones. Acepta la dificultad de conseguir la esclavizada bozal y pide que se le compre "una criollita, bien sea de las Temporalidades, o de algún vecino de esa Ciudad y que no pase de diez años” y que, si allí no se consiguiere, que se la buscase en Córdoba. AHPBA, 3-1-6-18, Juan Antonio Ruiz Tagle a Francisco de Prieto y Pulido, La Plata, 11 de febrero de 1774. Aparentemente Prieto no la
} 
cuesta satisfacer lo encargado por su amigo, quien reconoce desde La Plata: "Ya tenemos por acá noticia de que el Contrabando de la Colonia se halla extinguido casi enteramente" ${ }^{14}$ Esta imagen es coherente con el análisis de los decomisos, que parecen señalar un relativo éxito en la represión en el río y sus orillas por las autoridades españolas desde los años 1760 (Jumar y Paredes, 2008).

Más allá de ello, sin duda la expedición de Cevallos de 1776-1777 cortocircuitó por lo menos durante algún tiempo el flujo del contrabando en general y en particular el de esclavizados por el circuito portugués, languideciera o no con anterioridad, al tiempo que parece tardar el fruto de las reacomodaciones subsiguientes, resultado del traslado de las redes portuguesas a Montevideo, conociéndose la operatoria de algunos individuos, entre los que destaca Manuel Cipriano de Melo (Bentancur, 1985; Borucki, 2011; Prado, 2012).

Otra variable que Borucki (2016, pp. 18 y ss.) hace intervenir en su análisis a partir de 1785, y sobre todo de 1792 gracias al permiso de comercio con neutrales, es que la corona intenta que la trata se lleve adelante por empresarios españoles. Un resultado es que ahora son ellos, y no ella quien negocia con proveedores extranjeros. Se puede sumar que ya desde antes de esos años se promueve el tráfico en manos de españoles que necesariamente dependerán de extranjeros, tras el abandono de la política de provisión mediante contratos o tratados en los que la corona intervenía

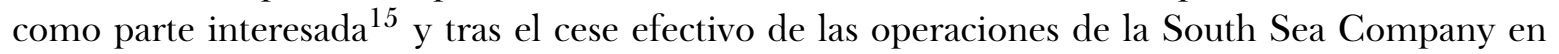
1739 Durante el periodo abordado en este trabajo la corona promueve la trata en o desde Río de la Plata al proyectar incluir en el nuevo virreinato las islas de Fernando Poo y Annobon en 1778 (Crespi, 2010), mediante una fallida expedición que salió de Montevideo y que finalmente reportó 60 esclavizados (26 en $1 7 7 9 \longdiv { 1 7 }$ y 24 en 1783).

De este modo, por los datos y análisis que aporta A. Borucki (2015), entre 1779 y 1783, el contrabando de esclavizados por las redes portuguesas ha menguado y no llegan muchas piezas por el circuito legal español. Aunque sus explicaciones sintetizan características esenciales de la trata desde años posteriores, las informaciones que se presentan en este trabajo colaboran al momento de observar cómo se monta el escenario para que A. Borucki proponga que desde 1791 una parte importante del crecimiento del tráfico se relaciona con que:

consiguió en Buenos Aires y en julio Ruiz Tagle agradece por las gestiones al efecto realizadas ante el presidente de las Temporalidades de Córdoba. AHPBA, 3-1-6-19, Juan Antonio Ruiz Tagle a Francisco de Prieto y Pulido, La Plata, 11 de julio de 1774. En diciembre por fin se encontró una esclavizada que convenía; se pagaría con dinero que Prieto tenía de Ruiz Tagle. AHPBa, 3-1-6-19, Juan Antonio Ruiz Tagle a Francisco de Prieto y Pulido, La Plata, 11 de diciembre de 1774. En las notas de aduana procesadas, en dos oportunidades los declarantes señalan que los esclavizados registrados se venden por haber caído en desgracia. Los hermanos Escalada remiten a Chile dos mulatos "llamados Martín y Josef como de veinticinco años cada uno que así mismo remito por aviesos”. AGN-A, XIII-33-11-2. Notas de salida de 1780, nota 534 del 28 de febrero de 1780. Francisco Urdaneta remite a Lima a "Benito mi esclavo, que me ha servido desde que arribé a estas Provincias, y por infiel lo despacho para solicitar su venta”. AGN-A, XIII-34-3-1. Notas de salida de 1782, nota 2913 del 8 de noviembre de 1782. Seguramente hay más casos, sólo que los declarantes se muestran más perspicaces que los mencionados y ocultan los vicios de la mercadería ante los posibles compradores.

14 AHPBA, 3-1-6-18, Juan Antonio Ruiz Tagle a Francisco de Prieto y Pulido, La Plata, 11 de enero de 1774.

15 Es de utilidad abordar la intervención de la corona española en la trata desde el clásico Scelle (1906).

16 La primera licencia de este tipo para Río de la Plata se acordó a Tomás Navarro en 1741, siguiéndole otras a Ramón de Palacio (testaferro de Manuel Díaz de Saravia) en 1750, en 1753 a Francisco de Mendinueta quien remitió a Río de la Plata varias embarcaciones entre 1755 y 1765 . Véase Jumar (2010, pp. 245-247).

17 Uno de ellos al menos fue enviado a Chile: "Martín de Sarratea remite a Mendoza con el Carretero José Ribas a entregar a Dn Hilario de Almandoz para dirigir a Dn Bernardino de Altolaguirre, contador de la Real Casa de Moneda de Santiago de Chile, un negro llamado Lázaro que para ese fin le envió últimamente desde Montevideo Dn Juan Pedro de Aguirre de la urca San Pedro, que de Cádiz vino con víveres para las Islas de Anobón y Fernando del Poo. Buenos Aires, 7 de marzo de 1780". AGN-A, XIII-33-11-2. Notas de salida de 1780, nota 652, 7 de marzo de 1780. 
es posible visualizar un tráfico de esclavos en el periodo virreinal desarrollándose en tándem en Montevideo y Buenos Aires, en tanto que los mercaderes de la capital virreinal tenían el control sobre las rutas que llevaban a los mercados interiores hasta Lima, y los mercaderes de Montevideo proveían sus redes con el mundo portugués tanto de Brasil como de África. En ese sentido, Buenos Aires y Montevideo eran interdependientes en lo concerniente a esta nueva operativa de la trata (Borucki, 2015, 34-35).

En la gráfica 1, la curva de los esclavizados ingresados al complejo portuario rioplatense muestra algo curioso ${ }^{18}$ Entre 1779 y 1783 la monarquía hispánica está en guerra con Gran Bretaña y aunque las opiniones están divididas sobre la intensidad del impacto de esa guerra en el comercio ultramarino rioplatense ${ }^{19}$ hay coincidencia en reconocer que al menos una perturbación hubo.20 En el momento más álgido de la contienda y sus posibles perturbaciones, la entrada de esclavizados en el complejo portuario rioplatense conoce un momento de esplendor. Alex Borucki (2016), para los años 1777-1791 -en cuyo análisis corresponden a una etapa morosa de la trata de esclavizados en Río de la Plata-, informa que se desembarcaron 10998 esclavizados en los puertos rioplatenses (785 en promedio anual). En los años abordados en este trabajo, 1779-1783, se desembarcaron al menos 7092 esclavizados en el complejo portuario rioplatense, que representan $64.48 \%$ del total para 1777-1791.

Las notas de aduana de Buenos Aires registran la salida de 5415 esclavizados entre 1779 y 1783. De ellos 3997 son registrados para su venta en los lugares de destino. El resto, 1418 esclavizados, se registran para el uso del declarante de la nota de aduana (966 casos), para uso del destinatario de lo registrado (412 casos) o para el de terceros (40 casos) ${ }^{21}$ No es posible precisar en qué medida los esclavizados distribuidos habían sido desembarcados de modo reciente, pero se señala que residuos de información recogidos en la fuente muestran que no hay que hacer una relación directa entre esclavizados distribuidos desde Buenos Aires e introducidos en el complejo portuario rioplatense. En primer lugar, porque no se ha procesado la distribución desde Montevideo (que se dirige sobre todo a su traspaís), ni las ventas para el uso de esclavizados en las propias ciudades de Buenos Aires y Montevideo. En segundo lugar, porque a partir de diversas informaciones recogidas en las notas de aduana se observa que, aunque debieron ser mayoría, no sólo se

\footnotetext{
18 Agradezco a Alex Borucki quien compartió el origen de sus datos, con lo que pude reelaborar los gráficos insertados en sus trabajos. Esos datos provienen de Emory University, https://slavevoyages.org/.

${ }^{19}$ En primer lugar, sobre si afectó los flujos del circuito legal y cómo. En segundo, sobre el tamaño del contrabando. Se observa la cuestión a detalle en Jumar (en prensa).

${ }^{20}$ Las dificultades en el circuito español se compensan con la entrada de navíos con licencia a tal efecto o mediante el mecanismo de arribadas forzosas maliciosas. Bajo alguno de estos casos de figura se introdujeron esclavizados por navíos portugueses. Por ejemplo, el administrador de la Aduana y de las alcabalas del virreinato del Río de la Plata, Francisco Ximénez de Mesa, certifica que Juan Martín de Pueyrredón pagó los derechos correspondientes (entrada y alcabala de primera venta) a diez esclavizados "correspondientes a los que en mayor partida introdujeron dn Manuel de Acuña, dn Antonio Acosta y dn Juan Ignacio, procedentes de las Embarcaciones Portuguesas, que estuvieron en este Puerto; cuyo trasbordo verificaron dichos Introductores en virtud de Superior permiso”. AGN-A, XIII-33-11-2. Notas de salida de 1780, nota 1268, 10 de mayo de 1780 .

21 Se puede confiar en los datos sobre la condición bajo la cual se ponen en circulación los esclavizados -como se confía en toda fuente fiscal- ya que emergen de informaciones que tienen que ver en primer lugar con la propiedad de la cosa y de modo indirecto con su condición tributaria.
} 
GRÁFICA 1. ARRIBO DE ESCLAVIZADOS A RÍO DE LA PLATA, 1777-1810

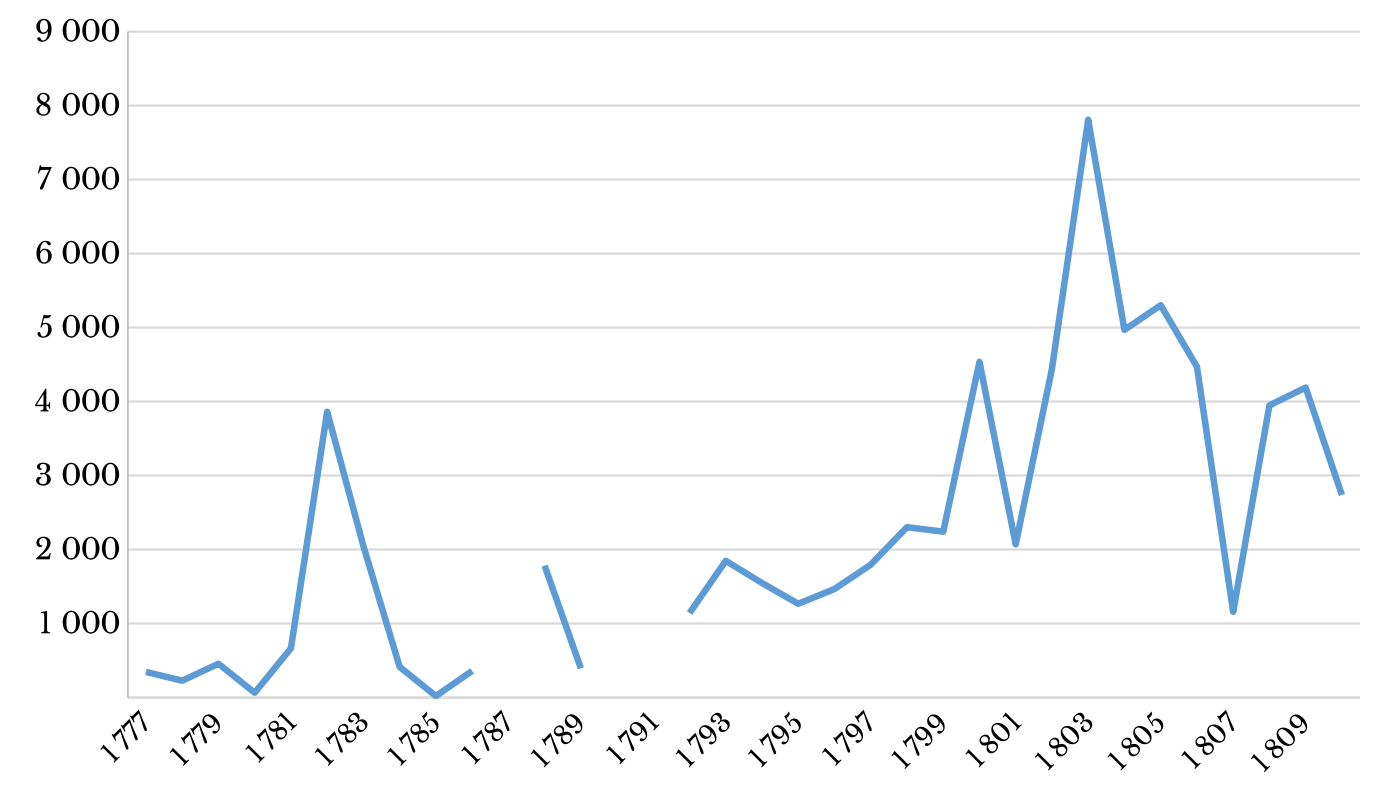

Fuente: Viajes esclavistas, Tráfico transatlántico de esclavos-base de datos (https://slavevoyages.org/voyage/ database) y Tráfico intraamericano de esclavos-base de datos https://slavevoyages.org/american/database.

ponen en circulación esclavizados recién desembarcados ${ }^{22}$ De allí que no se pongan en relación ahora las series de esclavizados desembarcados en el complejo portuario rioplatense y el total de distribuidos desde Buenos Aires. Aun así, no se puede dejar de señalar el desfasaje entre ambas series, ya que por las prevenciones señaladas sobre la diversidad de casos de figura que contiene

22 La fuente presenta excesos de información brindados por los declarantes ante la Aduana cuya naturaleza aleatoria no permite que sea empleada para elaborar series, sino solo para revelar casos de figura. Los que se corresponden con la idea de esclavizado recién desembarcado son los identificados en tanto que bozales, pero cubren sólo 481 casos. Se puede saber que entre los esclavizados distribuidos desde Buenos Aires hay nacidos en América (41 criollos, 152 mulatos). En pocos casos, doce, se los identifica como ladinos, es decir, reducidos a cautiverio desde tiempo antes de su aparición en las notas y transculturados. En la mayoría de los casos (4 719) se los identifica como esclavos (1 691) o negros (3 028). Entre ellos sin duda están los bozales faltantes, pero también entre ellos se identifican casos de ladinos por informaciones relacionadas con oficios, reventas, huidas, adquisición por herencia, introducción del esclavizado desde el interior americano y acompañando a sus amos en el viaje de ida a Río de la Plata para verlo luego volver con ellos, esclavitud doméstica. En relación con esto último, los esclavizados a veces se registran en tanto que criados y en algunos casos además se aclara que el esclavizado nació en la casa del declarante. No se pueden dar cifras de estos casos de figura porque en muchos se superponen variables (por ejemplo, "negro-criado-esclavo de mi servicio", "negro maestre calafate", "esclavo huido de San Juan”, “criado esclavo nacido en mi casa que me acompaña en mis viajes”, etc. Como curiosidad, las notas permiten rastrear en los porteños el continuado gusto por vacacionar en la banda norte del río. Pedro Antonio Sauco anuncia su deseo de "pasar a Santo Domingo Soriano acompañando a mis hermanas $\mathrm{D}^{\mathrm{a}}$ María Martina y $\mathrm{D}^{\mathrm{a}}$ María Paloma Sauco, llevando únicamente el equipaje y bastimentos necesarios para los días que se mantengan en aquel destino adónde van a tomar los Aires y las Aguas [...] como asimismo [registro] una criada llamada Francisca, criolla de aquí y esclava propia”. AGN-A, XIII-34-4-1. Notas de salida de 1783, nota 8 del 2 de enero de 1783. 
la serie de distribución desde Buenos Aires, hay un saldo sin ver salir de Río de la Plata que es mayor a los 1677 esclavizados que resultan de simplemente restar los redistribuidos (5 415) a los desembarcados (7 092).

Una explicación posible es un vacío de información. Las notas de aduana procesadas no muestran la distribución desde Montevideo hacia su traspaís ni la venta para el consumo en las ciudades de Buenos Aires y Montevideo. De modo que el desfasaje impone que se traten con mucha cautela las cifras obtenidas, sobre todo al momento de establecer comparaciones entre los circuitos intra y extrarregionales, así como la circulación intrarregional en sí. La operatoria de la trata sostiene la idea de que la laguna en la información no afecta la observación de la circulación extrarregional rioplatense; por más que algún esclavizado se remitiese directamente desde Montevideo hacia los espacios interiores - por la vía fluvial- y exteriores -marítima hacia el Bajo Perú por el Cabo de Hornos-, la mayoría sale desde Buenos Aires, tras haber sido transferida desde Montevideo.

De modo que, al menos para comparar ritmos, lo apropiado parece ser sólo tomar las cifras de la circulación extrarregional para relacionarlas con las de desembarcados. Como se verá más adelante, la esfera extrarregional cuenta con 4559 esclavizados, $84.19 \%$ de un total de 5415 .

La gráfica 2 muestra dos microcoyunturas. La primera, de marzo de 1779 a mediados de 1781 , muestra un desplazamiento temporal en la salida de los esclavizados desembarcados. Se observa el impacto de la doble perturbación en los circuitos que entorpecen y retrasan las operaciones. La segunda, de mediados de 1781 a fines de 1783, parece retomar el crecimiento allí donde había quedado en 1779. Sugiere que, si se mantienen las tendencias de tan breve periodo, y se recuerda la crítica de los datos en relación con la circulación intrarregional, esta esfera cobraría cada vez mayor importancia y que Río de la Plata se pudo convertir en un mercado atractivo en sí aunado a su función redistribuidora, que es lo que se muestra para el periodo observado, puesto que la esfera extrarregional se lleva al menos $84.19 \%$ de los esclavizados desembarcados.

En el conjunto de las operaciones, este comercio, integrado a los otros con los que se entrelaza en los registros aduaneros, colabora a crear una tendencia general en los mercados hacia los que se ve salir a los esclavizados en la que, a pesar de la guerra en el Atlántico y las rebeliones altoperuanas de 1780-1781, se mantiene un nivel de negocios que si bien acusa el doble impacto, no es tan fuerte como para generar problemas serios ni para proponer la existencia de una crisis en la circulación (Jumar, 2019b).

En el resto del trabajo se presenta, en primer término, el detalle de las cifras de la circulación de esclavizados vista desde la Aduana de Buenos Aires entre 1779 y 1783, y a continuación, los detalles de uno de los negocios que contienen llevado adelante en 1783.

\section{La SALIDA DE ESCLAVIZADos DESDE Buenos Aires ENTRE 1779 y 1783}

Según las notas de aduana registradas en la Aduana de Buenos Aires, entre marzo de 1779 y diciembre de 1783, 783 declarantes consignan la salida de 5415 esclavizados de Buenos Aires.23 De esos declarantes, 531 (67.87\%), aparecen una vez, lo que registra en total 906 esclavizados

\footnotetext{
23 Hay 1349 mujeres, 3471 hombres y 595 esclavizados fueron registrados en partidas en las que solo se aclara que eran de ambos sexos, pero sin discriminar. No pareció prudente explotar los datos relacionados con la edad, ya que en la mayoría de los casos no se la consigna y cuando se lo hace parece existir la tendencia a especificar el dato cuando se trata de esclavizados hasta los 16 años.
} 


\section{GRÁFICA 2. ESCLAVIZADOS ENTRADOS AL COMPLEJO PORTUARIO RIOPLATENSE Y SALIDAS DE LA CIRCULACIÓN EXTRARREGIONAL RIOPLATENSE, 1777-1785}

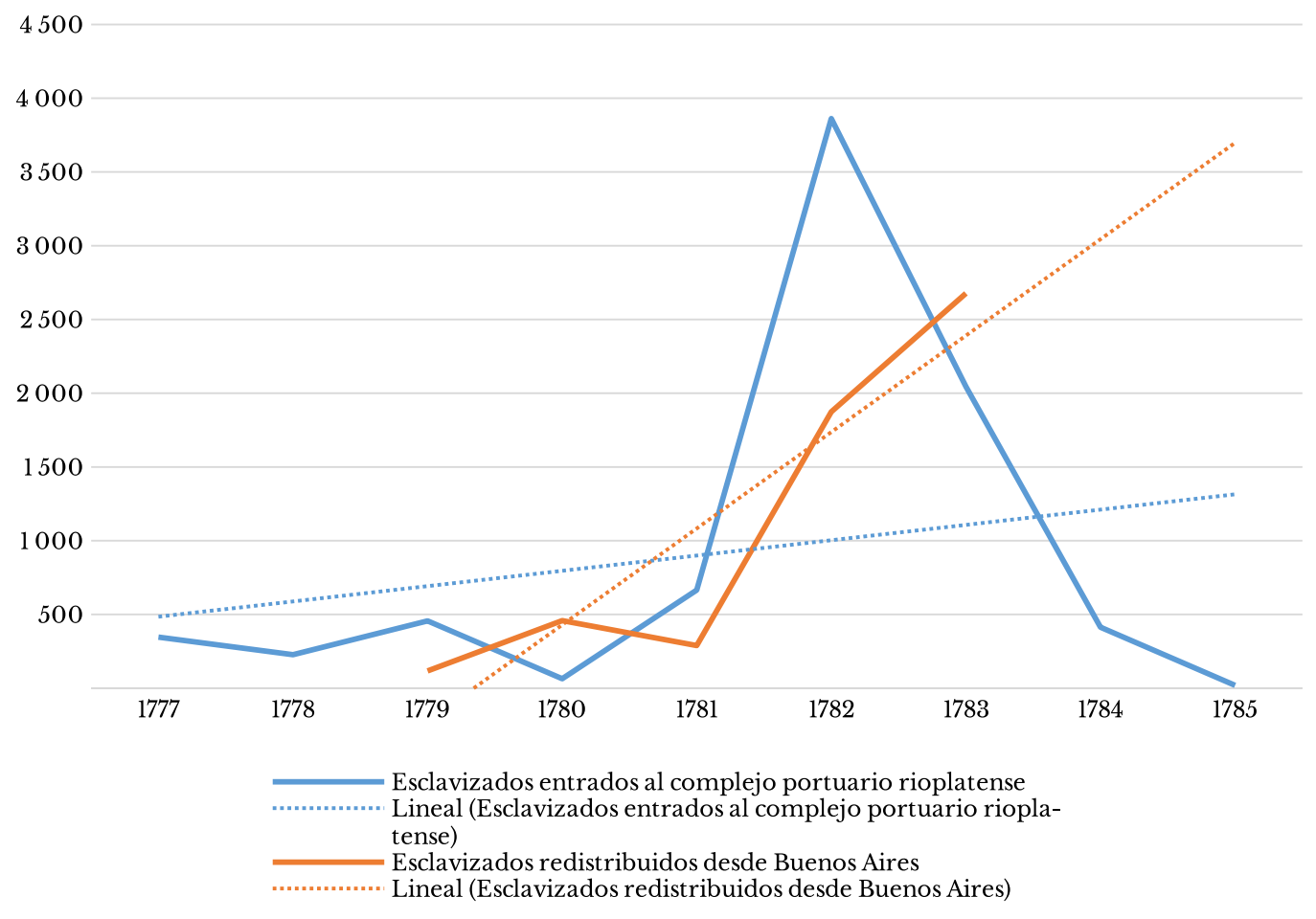

Fuente: Viajes esclavistas, Tráfico transatlántico de esclavos-base de datos https://slavevoyages.org/voyage/ database y Tráfico intraamericano de esclavos-base de datos https://slavevoyages.org/american/database y RegAduAR, base de datos 1779-1783.

(16.73\%). Otros aparecen dos ${ }^{24}$ o tres veces ${ }^{25}$ mayormente registrando pocos esclavizados cada vez. El cuadro 1 muestra que a pesar de ver a muchas personas circulando con esclavizados o enviándolos a otros, hay algunos declarantes más activos que otros, ya sea porque aparecen muchas veces o porque mueven más esclavizados. Son los que con mayor seguridad pueden ser considerados como tratantes o al menos comerciantes con intereses particulares en la trata, además de los otros que pudieran tener. Pero las cifras no invitan a pensar en un mercado concentrado en pocas manos, aunque sí controlado por hombres. La participación femenina entre los declarantes (87 casos con 185 esclavizados en total) muestra ante todo mujeres que se desplazan con esclavizados de su servicio (155 esclavizados, de los que 94 eran mujeres) o que los remiten para el de terceros (trece esclavizados, cinco mujeres), ya que solo diez mujeres registran en total 17 esclavizados para su venta (once eran mujeres).

24131 declarantes (16.73\%) que en total registran 752 esclavizados (13.89\%).

2549 casos $(6.26 \%)$ que registran 395 esclavizados $(7.29 \%)$. 


\section{CUADRO 1. CANTIDAD DE APARICIONES DECLARANTES Y ESCLAVIZADOS REGISTRADOS. NOTAS DE ADUANA, ADUANA DE BUENOS AIRES (SALIDA), 1779-1783}

\begin{tabular}{rrrrr}
\hline \multicolumn{2}{r}{ Declarantes } & \multicolumn{2}{c}{ Esclavizados } \\
Apariciones & Cantidad & Porcentaje & Cantidad & Porcentaje \\
\hline 1 & 531 & 67.82 & 906 & 16.73 \\
2 & 131 & 16.73 & 752 & 13.89 \\
3 & 49 & 6.26 & 395 & 7.29 \\
4 & 30 & 3.83 & 531 & 9.81 \\
5 & 10 & 1.28 & 79 & 1.46 \\
6 & 8 & 1.02 & 87 & 1.61 \\
7 & 3 & 0.38 & 141 & 2.60 \\
8 & 2 & 0.26 & 100 & 1.85 \\
9 & 4 & 0.51 & 896 & 16.55 \\
10 & 4 & 0.51 & 165 & 3.05 \\
11 & 1 & 0.13 & 90 & 1.66 \\
12 & 3 & 0.38 & 292 & 5.39 \\
13 & 2 & 0.26 & 759 & 14.02 \\
14 & 2 & 0.26 & 50 & 0.92 \\
15 & 2 & 0.26 & 103 & 1.90 \\
21 & 1 & 0.13 & 69 & 1.27 \\
Totales & 783 & 100 & 5415 & 100 \\
\hline
\end{tabular}

Fuente: RegAduAR, base de datos 1779-1783.

El cuadro 2 muestra la información organizada en función de los circuitos principales anudados en Buenos Aires (véanse cuadros 3 y 4) y de los motivos por los cuales se pudo saber que los esclavizados fueron puestos en movimiento. Así, 966 esclavizados son registrados como para ser usados por el declarante, quien además se mueve con ellos ${ }^{26}$ En otros casos, se ve que el declarante registra el envío para el uso del destinatario de lo registrado en la nota (412 esclavizados) y en 40 casos se sabe que el usuario final es alguien distinto del declarante y del destinatario. Quedan 3997 esclavizados que se registran para la venta.

\footnotetext{
26 Por ejemplo, "Sírvase mandar extender guía para un negrito llamado Domingo como de catorce años y una negra llamada Ana como de edad de diez y ocho años que llevo a Chile para mi servicio y de mi familia como vecino de allí en carretas de José Ribas... Buenos Aires y marzo 8 de 1780. Justo Medina.” AGN-A, XIII-34-11-2. Notas de salida de 1780 , nota 654,8 de marzo de 1780 .
} 


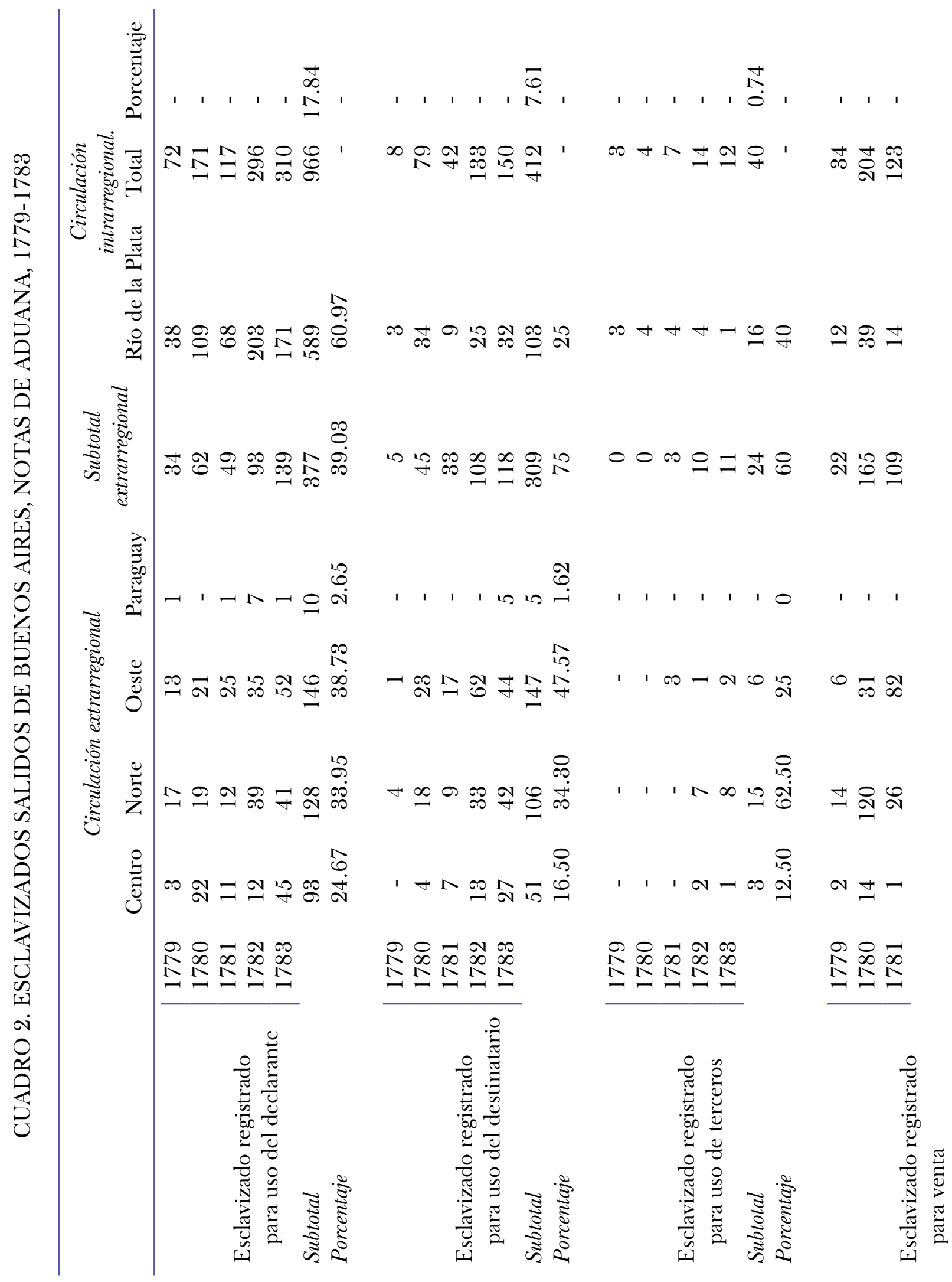




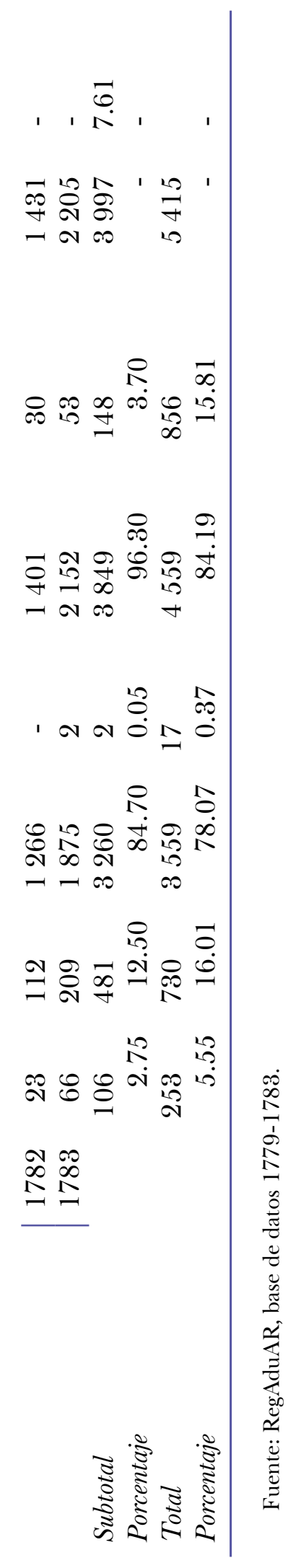


CUADRO 4. ORGANIZACIÓN DE LA INFORMACIÓN POR ESPACIOS. CIRGULACIÓN INTRARREGIONAL

\begin{tabular}{|c|c|}
\hline Espacios intrarregionales & Cantidad de esclavizados \\
\hline Río de la Plata Banda Norte & 3 \\
\hline Río de la Plata Banda Norte Canelones & 2 \\
\hline Río de la Plata Banda Norte El Espinillo & 4 \\
\hline $\begin{array}{l}\text { Río de la Plata Banda Norte Partido } \\
\text { del Rosario }\end{array}$ & 6 \\
\hline Río de la Plata Banda Norte San Salvador & 9 \\
\hline Río de la Plata Banda Norte Soriano & 40 \\
\hline Río de la Plata Litoral Arroyo de la China & 5 \\
\hline Río de la Plata Litoral Bajada del Paraná & 1 \\
\hline Río de la Plata Litoral Corrientes & 14 \\
\hline Río de la Plata Litoral Gualeguay Grande & 8 \\
\hline Río de la Plata Litoral Gualeguaychú & 3 \\
\hline Río de la Plata Litoral Ibicuy & 1 \\
\hline Río de la Plata Litoral Paysandú & 4 \\
\hline $\begin{array}{l}\text { Río de la Plata Litoral Pueblos } \\
\text { de las Misiones }\end{array}$ & 2 \\
\hline $\begin{array}{c}\text { Río de la Plata Litoral Pueblos } \\
\text { de las Misiones San Borja }\end{array}$ & 3 \\
\hline Río de la Plata Litoral Santa Fe & 34 \\
\hline $\begin{array}{l}\text { Río de la Plata Banda Sur Campaña } \\
\text { de Buenos Aires Norte Areco }\end{array}$ & 2 \\
\hline $\begin{array}{c}\text { Río de la Plata Banda Sur Campaña } \\
\text { de Buenos Aires Norte Arrecifes }\end{array}$ & 5 \\
\hline $\begin{array}{l}\text { Río de la Plata Banda Sur Campaña } \\
\text { de Buenos Aires Norte Fontezuelas }\end{array}$ & 4 \\
\hline $\begin{array}{l}\text { Río de la Plata Banda Sur Campaña } \\
\text { de Buenos Aires Norte Luján }\end{array}$ & 4 \\
\hline $\begin{array}{l}\text { Río de la Plata Banda Sur Campaña } \\
\text { de Buenos Aires Norte Melincué }\end{array}$ & 2 \\
\hline $\begin{array}{l}\text { Río de la Plata Banda Sur Campaña } \\
\text { de Buenos Aires Norte San Nicolás }\end{array}$ & 2 \\
\hline $\begin{array}{l}\text { Río de la Plata Banda Sur Campaña } \\
\text { de Buenos Aires Norte San Pedro }\end{array}$ & 1 \\
\hline $\begin{array}{l}\text { Río de la Plata Complejo Portuario } \\
\text { Rioplatense Colonia }\end{array}$ & 29 \\
\hline $\begin{array}{l}\text { Río de la Plata Complejo Portuario } \\
\text { Rioplatense Las Vacas }\end{array}$ & 6 \\
\hline $\begin{array}{l}\text { Río de la Plata Complejo Portuario } \\
\text { Rioplatense Maldonado }\end{array}$ & 14 \\
\hline
\end{tabular}




\begin{tabular}{lc} 
Río de la Plata Complejo Portuario & \\
$\quad$ Rioplatense Montevideo & 593 \\
Río de la Plata Complejo Portuario & \\
$\quad$ Rioplatense Navío & 25 \\
Río de la Plata Complejo Portuario & \\
$\quad$ Rioplatense Víboras & 25 \\
Río de la Plata Sur Costa Patagónica & 3 \\
Río de la Plata Sur Malvinas & 2 \\
Total & 856 \\
\hline
\end{tabular}

Fuente: RegAduAR, base de datos 1779-1783.

En los casos de esclavizados para el uso personal de declarantes que están regresando a sus moradas no se puede saber en cuántos casos el esclavizado ya había sido llevado en el viaje de ida, pero el caso de figura existe por consignárselo en algunas notas ${ }^{27}$ Sin embargo, parece razonable imaginar que en su mayor parte fueron comprados en Río de la Plata para ser llevados al lugar de residencia del declarante o que acompañan a un rioplatense en un viaje. Cuando se remiten esclavizados para el uso del destinatario de lo contenido en la nota o de terceros, se deduce sobre la base de varias notas que fueron comprados por encargue aunque también en las notas destinadas a la circulación intrarregional hay algunas que dejan sospechar que se puede estar también ante el préstamo o alquiler de esclavizados para tareas puntuales 28

Para ponderar las cifras del cuadro 2, hay que tener en cuenta las prevenciones ya señaladas respecto a las lagunas de información. El primer sondeo de las notas de Montevideo muestra que sus datos impactan sobre todo en la circulación intrarregional y de la extrarregional, en la ultramarina. De modo que cabe esperar que las cifras totales emergentes de las receptorías de todo el complejo portuario rioplatense aumenten el desbalance en favor de la circulación intrarregional (véase mapa 1).

Del circuito intrarregional, requiere alguna explicación el número de esclavizados enviados desde Buenos Aires a Montevideo (593, 69.28 \%) (véase cuadro 3). En su mayor parte (479 unidades, $79.6 \%$ se trata de esclavizados que se mueven con sus amos $(418,70.49 \%)$ o que son registrados para ser utilizados por el destinatario $(46,7.76 \%)$ o por un tercero $(8,1.35 \%)$. Los 121 esclavizados $(20.40 \%)$ que se remiten a Montevideo para su venta muestran al mismo tiempo que hay expediciones esclavistas que atracan en la banda sur del río y la atracción del mercado regional, ya que no tendría sentido que los esclavizados se envíen de Buenos Aires a Montevideo para

27 Por ejemplo, "Sírvase VM darme Licencia para llevar a la Ciudad de San Juan libremente un Negrito Criollo de dicha Ciudad y Esclavo de Dn José Clemente Moyano, vecino de la citada Ciudad, quien lo introdujo en esta de Buenos Aires hace tres años y lo dejó para imponerse en el Oficio de Zapatero de lo que en caso de ser necesario daré la prueba correspondiente con algunos sujetos de esta dicha ciudad como son Dn Juan José de Lanza, el Sargento Dn Francisco Gallardo y Dn Manuel Vicente de la Colina. Pedro José González.” Buenos Aires, 26 de mayo de 1780. AGN-A, 33-11-2. Notas de salida de 1780, nota 1.444 del 26 de mayo de 1780.

28 Por ejemplo, en la nota 3.143 de noviembre de 1780 Manuel Ferreira de la Cruz envía al maestre de la fragata La Paloma un esclavizado que es maestro calafate. En la nota 3.608 de diciembre de 1782 Manuel García Prida envía a su primo hermano José Prida, de San Juan, tres esclavizados para trabajar en las viñas. AGN-A, XIII-34-11-2. Notas de salida de 1780, nota 3.143 del 12-11-1780. AGN-A, XIII-34-3-1. Notas de salida de 1782, nota 3.608 del 28 de diciembre de 1782.

${ }^{29}$ En el lote hay esclavizados que ya llegan a Río de la Plata con sus amos desde el interior americano, en algunos casos para seguir viaje a Europa. 


\section{GUADRO 3. ORGANIZAGIÓN DE LA INFORMACIÓN POR ESPACIOS.} CIRCULACIÓN EXTRARREGIONAL

\begin{tabular}{|c|c|}
\hline Región & Esclavizados \\
\hline \multicolumn{2}{|l|}{ 1. Centro } \\
\hline Centro Córdoba (Córdoba) & 72 \\
\hline Centro Córdoba (Río Cuarto) & 4 \\
\hline Centro Córdoba (Río Tercero) & 3 \\
\hline Centro Norte (Santiago del Estero) & 54 \\
\hline Centro Norte (San Miguel de Tucumán) & 111 \\
\hline Centro Oeste (Catamarca) & 9 \\
\hline Total & 253 \\
\hline \multicolumn{2}{|l|}{ 2. Norte } \\
\hline Norte (Jujuy) & 58 \\
\hline Norte (Salta) & 209 \\
\hline Norte Alto Perú & 77 \\
\hline Norte Alto Perú (Azángaro) & 1 \\
\hline Norte Alto Perú (Chayanta) & 1 \\
\hline Norte Alto Perú (Chucuito) & 1 \\
\hline Norte Alto Perú (Cochabamba) & 4 \\
\hline Norte Alto Perú (La Paz) & 97 \\
\hline Norte Alto Perú (La Plata) & 51 \\
\hline Norte Alto Perú (Oruro) & 3 \\
\hline Norte Alto Perú (Potosí) & 226 \\
\hline Norte Alto Perú (Puno) & 2 \\
\hline Total & 730 \\
\hline \multicolumn{2}{|l|}{ 3. Oeste } \\
\hline Bajo Perú (Arequipa) & 74 \\
\hline Bajo Perú (Lima) & 1776 \\
\hline Bajo Perú (Tarapacá) & 7 \\
\hline Chile & 86 \\
\hline Chile (Copiapó) & 9 \\
\hline Chile (Santiago de Chile) & 477 \\
\hline Chile (Valparaíso) & 18 \\
\hline Cuyo (Mendoza) & 943 \\
\hline Cuyo (San Juan) & 165 \\
\hline Cuyo (San Luis) & 2 \\
\hline Cuyo (Tunuyán) & 2 \\
\hline Total & 3559 \\
\hline \multicolumn{2}{|l|}{ 4. Paraguay } \\
\hline Paraguay (Asunción) & 16 \\
\hline Paraguay (Villa Rica) & 1 \\
\hline Total & 17 \\
\hline Total general & 4559 \\
\hline
\end{tabular}

Fuente: RegAduAR, base de datos 1779-1783. 


\section{MAPA 1. CIRCULACIÓN INTRARREGIONAL DE ESCLAVIZADOS OBSERVADA DESDE LA ADUANA DE BUENOS AIRES, 1779-1783}

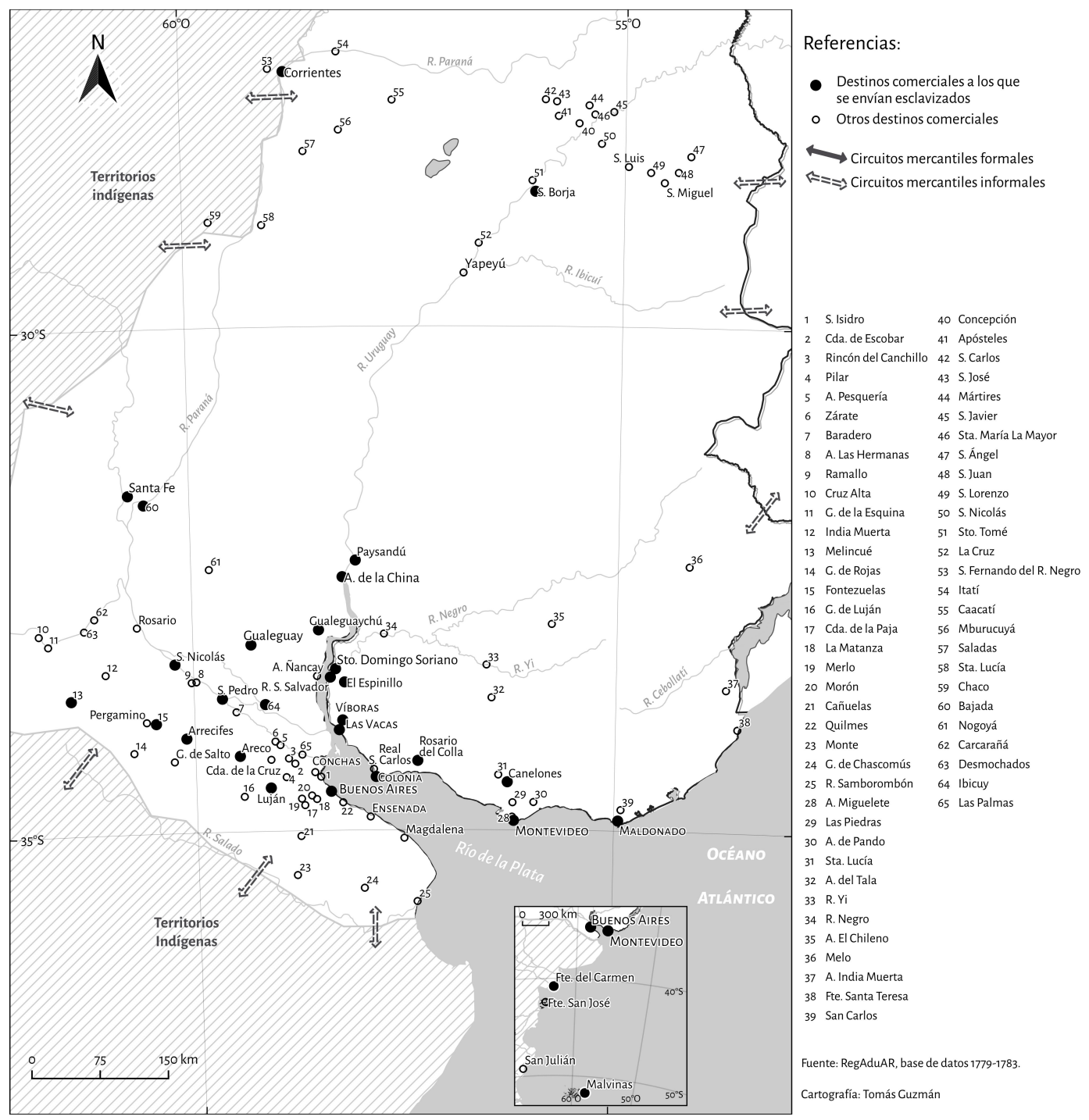

Fuente: elaborado con base en la dispersión general de los envíos registrados en la Aduana de Buenos Aires. RegAduAR, base de datos, 1779-1783. Cartografía: Tomás Guzmán, en Jumar (2019b).

luego ser reexpedidos hacia el interior americano. Otra característica de esta circulación es que en el circuito intrarregional es donde existe mayor presencia de mujeres registrando esclavizados, 70 declarantes con 157 unidades, que en su mayoría (140 esclavizados) acompaña a sus amas para servirlas.

Si se sumasen los faltantes provenientes de las notas de aduana de Montevideo y las receptorías menores, así como de las ventas en esa ciudad y la de Buenos Aires (entre los que podrían estar la mayor parte del saldo entre esclavizados desembarcados y distribuidos desde Buenos Aires), solo podría aumentar la participación proporcional de la circulación intrarregional rioplatense en todos 
los rubros, con lo que se estaría viendo un fenómeno sobre el que llama la atención Borucki (2015) para los años finales del siglo XviII y los datos expuestos parecen mostrar cómo se va gestando, lo que puede interesar a los estudiosos de la composición de la mano de obra a nivel regional. $\mathrm{Al}$ tomar como base un memorial del Gremio de Hacendados de 1794 como eje ${ }^{30}$ Borucki (2015) propone que los poderosos rioplatenses de fines del siglo xvIII tienen una marcada preferencia por la mano de obra esclavizada y que de un modo ciertamente muy extraño, los ven como colonos preferibles a la mano de obra libre. El cuadro 1 podría mostrar que tal vez ya tenían esa preferencia desde antes. En la circulación intrarregional se observa, por un lado, que los consumidores, sea en persona o a través de terceros hacen sus encargues en Buenos Aires (para uso del declarante, para uso del destinatario, para uso de terceros). Por otro lado, la venta también muestra que el mercado regional es atractivo para que se envíen esclavizados para encontrar comprador. Así, se vería ya en los años observados (1779-1783) la importancia que tenía en la región esa mano de obra esclavizada que se dice querer aumentar en la última década del siglo. Puede ser interesante notar que investigaciones paralelas muestran lo mismo desde distintos puntos de observación. Alex Borucki $(2011,2015,2016,2017)$ desde la trata esclavista en particular y Maximiliano Camarda (2010) desde la perspectiva de los flujos ultramarinos, resaltan y analizan la complementariedad y compenetración entre empresarios ganaderos y tratantes de esclavizados ya a fines del siglo XVIII.

Si se comparan las curvas intra y extrarregionales (véase gráfica 3), resalta el crecimiento abrupto de la segunda en 1781-1783. Según se observa en la gráfica 1, en el resto del periodo que cubre (1779-1812) participan ambos grandes circuitos en la formación de la tendencia general. No sería racional esperar que la distribución intrarregional domine en algún momento, pero si se mantuviese la tendencia al crecimiento en este circuito serían informaciones útiles para la historia económica regional.

Desde otro orden de problemas, relacionados con la circulación entre Río de la Plata y el interior americano, el contexto lo da un análisis general de la circulación desde la perspectiva de la Aduana de Buenos Aires entre 1779 y 1783 (Jumar, 2019b) que, para observar la ruta del Oeste -la que interesa ahora-, sigue de cerca el trabajo de José Sovarzo (2019) que la estudia en profundidad.

La esfera extrarregional (véase mapa 2) abarca $84.19 \%$ de los esclavizados, lo que interesa ahora son los números de la ruta del Oeste (78.07\% extrarregional; $65.72 \%$ del total general). También, los datos del cuadro 1 distribuyen los esclavizados según la situación de dominio y uso bajo las que se encontraban (uso del declarante, uso del destinatario, uso de terceros, venta). La circulación en dirección de Paraguay señala que al parecer no hay una demanda real de mano de obra esclavizada. ${ }^{31}$ Los datos también muestran que en Centro y Norte el impacto de las rebeliones altoperuanas se ve en 1781, y solo en venta, pero al año siguiente ya se recupera y sobrepasa el nivel anterior. Pero, sobre todo, los datos invitan a pensar que las operaciones relacionadas con las rutas Centro y Norte reflejan sobre todo compras realizadas por individuos para su propio uso o el de terceros, sin que existan importantes lotes de esclavizados que se remitan para la venta en esos mercados. Eso tal vez señale incertidumbre ante la demanda que empuje a los tratantes a no

\footnotetext{
30 "Los diputados del Gremio de haz.dos de la Campaña, criadores de Ganad. En el expediente q.e antes de establecerse el R.1 Tribunal del consulado en esta Ill. Capital promovieron”, 1794. Biblioteca de la Real Academia de Historia, Madrid, Colección Mata Linares, T. XII, fs. 160 y ss. En A. Borucki (2015, p. 40, nota 71).

31 A menos que se provea desde el mundo luso de modo directo.
} 


\section{GRÁFICA 3. DISTRIBUCIÓN ANUAL DE ESCLAVIZADOS POR CIRCUITOS MAYORES, RÍO DE LA PLATA, 1779-1783}

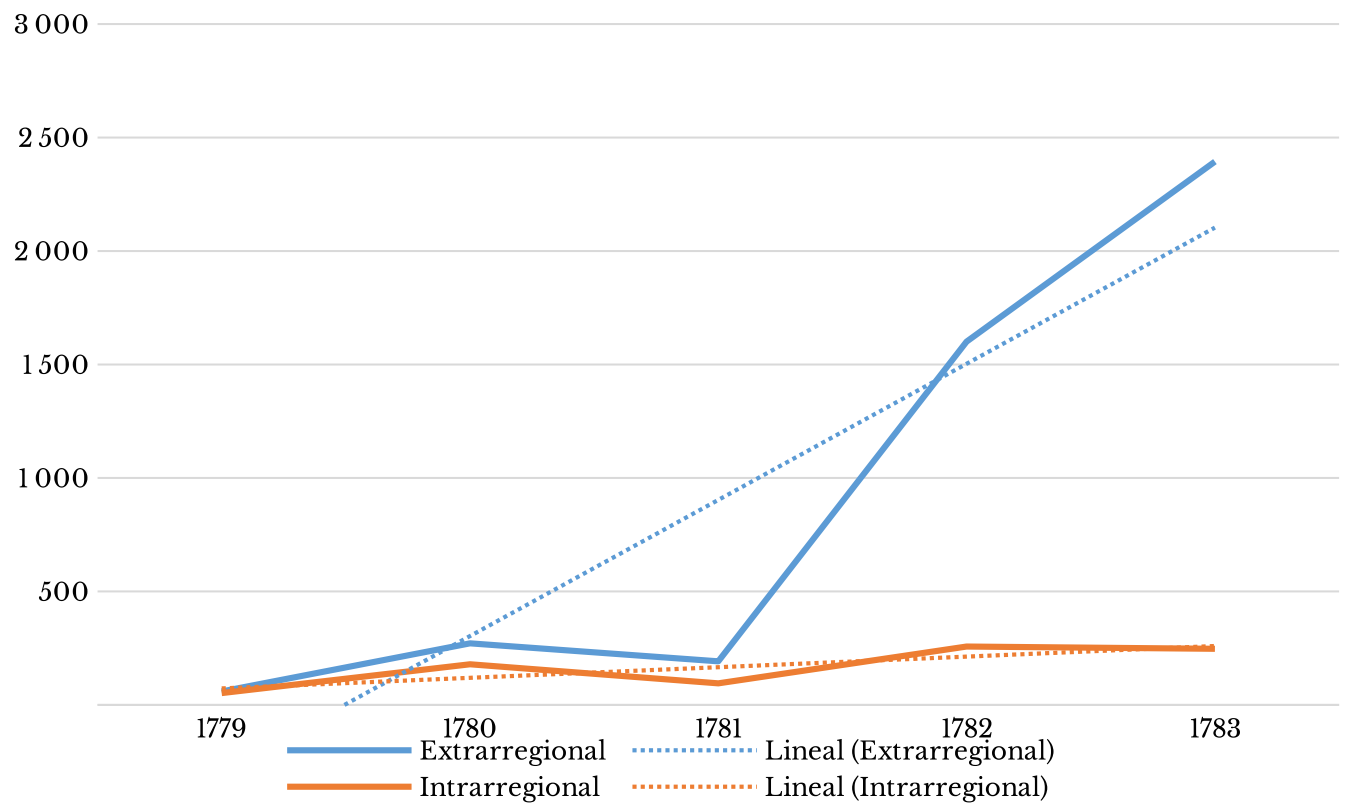

Fuente: Fuente: RegAduAR, base 1779-1783.

organizar expediciones mercantiles hacia esos mercados y los incentivos no sean suficientes como para asumir los costos y riesgos de operar de modo directo en ellos y sin que pueda atribuirse el fenómeno a las rebeliones desatadas en diciembre de 1780 .

El Oeste muestra todo lo contrario, ya que $91.6 \%$ de los esclavizados enviados por esa ruta son para su venta en el lugar de destino. También que, en el total de Oeste, $49.9 \%$ de los registros muestra la atracción directa de Lima por un camino largo y algo tortuoso por tierra y agua. De modo indirecto, parece evidente que era enviada al Bajo Perú buena parte de los esclavizados registrados para Chile (590 esclavizados), Mendoza (943) y San Juan (165) (véase cuadro 3). Intervienen en esta ruta 248 individuos, de los cuales 55 registran ya en Buenos Aires 1776 esclavizados (49.9\% del total de Oeste) para ser enviados a Lima pasando por Mendoza-San Juan 32 y Santiago de Chile-Valparaíso 33

32 En su análisis de la circulación vista desde las ciudades cuyanas empleando el modelo de los espacios económicos, José Sovarzo (2019) propone reservar el papel de nodos con el Pacífico a Mendoza en primer lugar y San Juan en segundo y con articulaciones entre ellas. Para él, sería más oportuno vincular la ciudad de San Luis con los espacios y ruta del Centro.

33 Por las características de la ruta del Oeste y los mercados que atraviesa se supone que la mayor parte de los 1106 esclavizados enviados a Mendoza y San Juan eran reexpedidos, pero ya en manos de agentes diferentes a los que los registran en Buenos Aires, cuyas redes no llegarían tras la cordillera. 


\section{MAPA 2. CIRCULACIÓN EXTRARREGIONAL DE ESCLAVIZADOS OBSERVADA DESDE LA ADUANA DE BUENOS AIRES, 1779-1783}

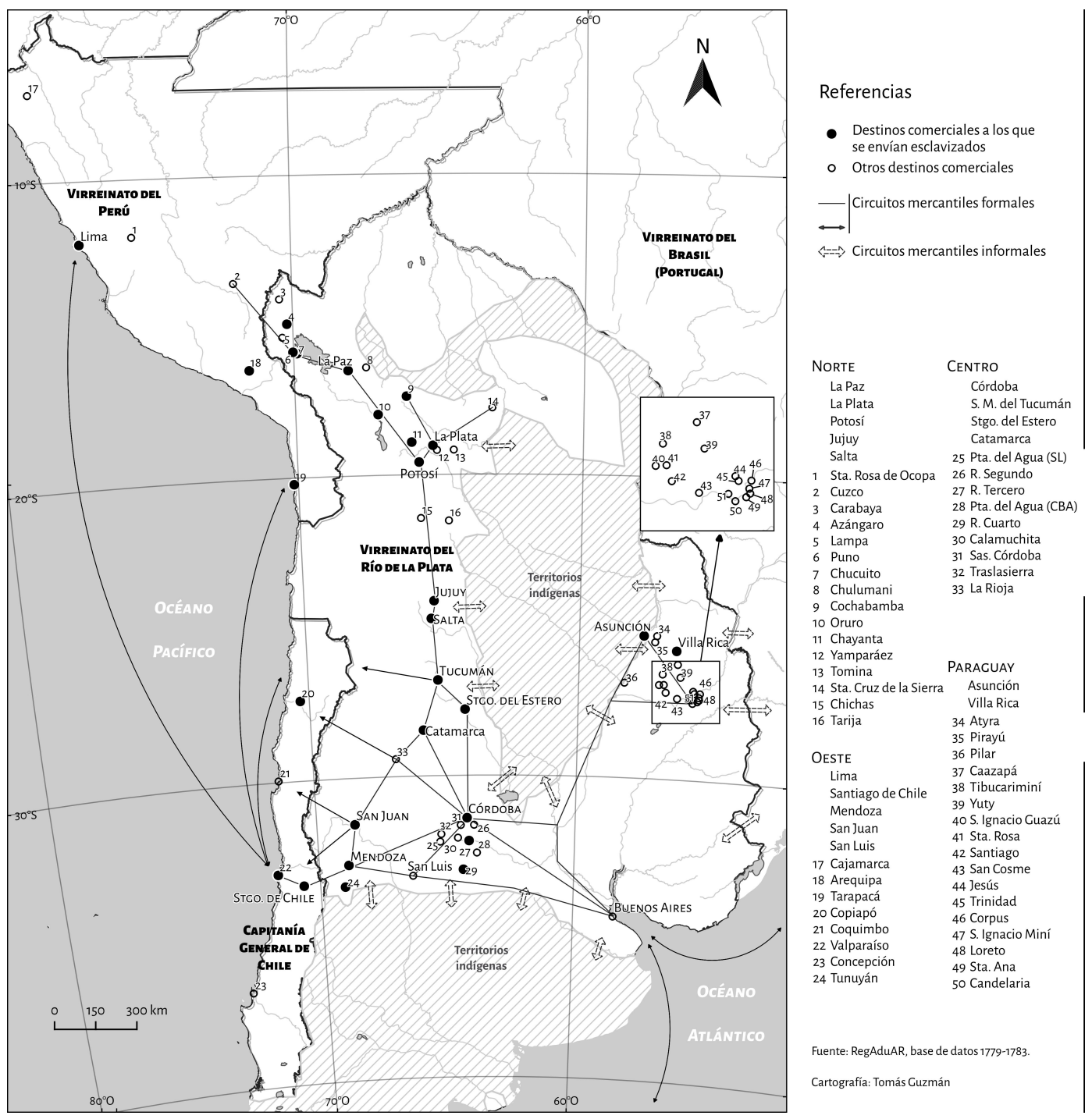

Fuente: elaborado con base en la dispersión general de los envíos registrados en la Aduana de Buenos Aires. RegAduAR, base de datos, 1779-1783. Cartografía: Tomás Guzmán, en Jumar (2019b).

En las notas para Lima, los mayores declarantes registran 1320 esclavizados: José García Zevallos (752), Juan Antonio Lezica (342) y Melchor de Somarriba (226). ${ }^{34}$ Les sigue un grupo de nueve individuos 85 que registran entre 21 y 39 esclavizados (270 en total), otros nueve ${ }^{36}$ que

34 Como se verá más adelante a partir de los esclavizados registrados por Melchor de Somarriba, es posible pensar que no todos los esclavizados transportados pertenecen a los declarantes, sino que se combinan operaciones propias con la venta a comisión por parte de terceros.

35 Martín José Urdaneta (21); Nicolás del Campo (23); Manuel Antonio Elzaurdi (28); Luis Francisco Gardeazabal y Lorenzo Arisnavarreta (30); Miguel Sancho Larrea (31); Antonio Artechea (32); Martín Sarratea (32); Marcelino Callexas Sanz (34); Félix Francisco Sánchez Celis (39). 
registran entre diez y 18 (117 esclavizados), catorce declarantes que registran entre dos y siete esclavizados (49 en total) y 20 con un esclavizado cada uno. En estos dos últimos grupos se encuentran diez esclavizados que se registran para el uso del declarante y uno para el de destinatario. $\mathrm{Al}$ parecer, era mucho lo que había en juego para esos individuos como para enfrentar tantas posibilidades de fracaso como había en esa ruta al enviar pequeños, medianos y grandes lotes de esclavizados asumiendo costos y riesgos del traslado y sin tener comprador asegurado. Se ven con la capacidad y posibilidades de intervenir en un circuito mayor y no se satisfacen con llegar con acciones propias hasta Mendoza o San Juan, que era lo posible para la mayoría que operaba desde Río de la Plata. Si entre ellos hay rioplatenses (nacidos o avecindados de vieja o nueva data), posiblemente estas notas señalen a quienes pertenecen al selecto grupo de grandes comerciantes o que quieren pertenecer a él.

\section{UNA VENTA DE ESCLAVIZADOS}

Entre los años 1778 y 1820 se pudo seguir la vida de Marcelino Callexas Sanz $z^{37}$ con sus fracasados esfuerzos por devenir un gran comerciante entre 1778 y 1792 (Jumar, 2016b). Entre 1778 y 1789 realizó la mayor parte de sus negocios en asociación con Ramón García Pérez ${ }^{38}$ a través de la firma Marcelino Callexas Sanz y C 39

Entre esos negocios figura la venta de 34 esclavizados (27 hombres y siete mujeres) en Lima en 1783, registrados en la nota de salida de Buenos Aires número 667 de febrero de ese año.40 Los habían llamado: “cuatro Manueles, tres Josés, dos Vicentes, seis Antonios, dos Migueles, dos Cayetanos, tres Juanes, dos Franciscos, un Pablo, Tomás y Amaro. Mujeres: dos Ritas, dos Marías, Catalina, Gracia y Eva" 41

36 Entre ellos está Domingo Belgrano Pérez (diez unidades) y Diego Agüero (18 unidades).

37 Castellano que desde La Coruña se instala en Buenos Aires en 1778 a sus 20 o 21 años y fallece en 1820.

38 Gallego que se instala primero en Montevideo en 1778 a los 17 o 18 años, en 1779 pasa a Buenos Aires y termina avecindado en Chuquisaca, tras haber andado por Chile y Lima.

39 En alguna correspondencia la firma toma el nombre del otro asociado, entonces: Ramón García Pérez y Ca .

40 AGN-A, XIII-34-4-1. Notas de salida de 1783, nota 667 del 18 de febrero de 1783 . No es la primera vez que se ve a Marcelino Callexas Sanz asociado a la trata. En octubre de 1782, Joaquín Pinto registra diez esclavizados para Santiago de Chile, "de los comprados a dn Marcelino Calleja, dn Antonio Sánchez y dn Manuel Gardiazabal”. AGN-A, XIII-343-1. Notas de salida de 1782, nota 2.550 del 1 de octubre de 1782. En enero de 1783 Marcelino Callexas Sanz parece estar devolviendo a Montevideo ocho esclavizados que habían sido introducidos por su compañía en Buenos Aires desde allí. AGN-A, XIII-34-1-1. Notas de salida de 1783, nota 101 del 11 de enero de 1783. Marcelino Callexas Sanz y su asociado García Pérez tienen en estos años estrechas relaciones con Manuel Diago, gallego avecindado en Montevideo que actúa como una suerte de primer favorecedor de Marcelino Callexas Sanz y Co (véase Jumar, 2016b). Diago, por su parte, aparece en varias operaciones esclavistas asociado a Pedro Álvarez Caballero. Entre otras, la que se analiza en detalle en este trabajo. Álvarez Caballero aparece a través de las notas de aduana como un actor regular asociado a la trata, aunque raramente con grandes lotes. De modo que es posible que Marcelino Callexas Sanz y C', por "efecto red" (si se me permite la expresión) puede haber entrado en el mundo de la trata por estas relaciones, ofreciendo una base de operaciones en Buenos Aires.

41 AGN-A, XIII-34-4-1. Notas de salida de 1783, nota 667 del 18 de febrero de 1783. 
En las notas se establece que Melchor de Somarribs 42 sería el conductor y primer consignatario y, como segundo, se señala a Juan Ignacio Escurra, quien se encontraría en Lima al momento de llegar los esclavizados. ${ }^{43}$ Además de los esclavizados por cuenta de Marcelino Callexas Sanz y Ca, Somarriba condujo en el mismo viaje al menos 226 esclavizados más, registrados de su cuenta y riesgo, con lo que se sabe que eran de su propiedad en todo o en parte ${ }^{44}$

Somarriba aparece por primera vez en Buenos Aires a través de las notas de aduana en marzo de 1782. Tiene la intención de pasar a Montevideo llevando consigo 10000 pesos fuertes. ${ }^{45}$ En noviembre y diciembre de 1782 y en enero de 1783 reaparece en Buenos Aires registrando para Montevideo 44750 pesos (13 800 $19350^{47}$ y 11600 pesos en 725 doblones de a $16^{48}$ ) para que sean entregados a Manuel Piedra. A su vez, este Manuel Piedra puede ser pariente de Diego Antonio de la Piedra 49 de Lima, a quien Somarriba consigna como destinatario de los 165 esclavizados registrados de su cuenta y riesgo.

$\mathrm{Al}$ cruzar las fechas con los registros anteriores, Somarriba en el primer viaje a Montevideo concretó la compra de los esclavizados que necesitaba (o confía a alguien los caudales para realizar la compra), habiendo estado en Montevideo entre marzo de 1782 y algún momento previo a noviembre del mismo año ${ }^{50}$ Es cuando reaparece en Buenos Aires enviando metales preciosos a Montevideo, presumiblemente para saldar el pago de los esclavizados que registró en el mismo mes en Buenos Aires para Lima, de su cuenta y riesgo. En marzo de 1783 Somarriba aparece por última vez en las notas, registrando - esta vez por cuenta y riesgo de D. A. de la Piedra y de Juan de la Piedra, varios textiles comprados en tiendas de Buenos Aires que también se remiten a Lima 51

42 Melchor de Somarriba, "residente y del comercio de esta ciudad [Lima]" (AHPBA, 3-3-6-75, 13 de septiembre de 1784). En 1785 se lo puede ubicar en Lima (AнPBA, 3-1-9-203. Carta y billete. Silvestre de Amenábar a Ramón García Pérez y C ${ }^{\circ}$ (Buenos Aires), Lima, 16 de marzo de 1785) y en 1791 aparece un Melchor de Somarriba entre los suscriptores del Mercurio Peruano (16 de febrero de 1791, número 11).

43 El 20 de noviembre de 1782 (nota 3.127) Juan Ignacio Escurra registra su equipaje para Mendoza. En agosto y septiembre de 1783 reaparece en Buenos Aires, registrando 12340 pesos (notas 2.635, 2.971, 2972, 3.079) para ser enviados a Montevideo y de allí embarcados hacia Cádiz y en la nota 3.142 del 29 de septiembre de 1783 registra su equipaje para Montevideo. No se sabe si siguió viaje a Cádiz o no, pero es la última vez que aparece en las notas. RegAduAR, base de datos 1779-1783.

44 AGN-A, XIII-34-3-1. Notas de salida de 1782, nota 3.133 del 20 de noviembre de 1782 y AGN-A, 13-24-4-1. Notas de salida de 1783, nota 662 del 17 de febrero de 1783.

45 AGN-A, XIII-34-2-5. Notas de salida de 1782, nota 712 del 11 de marzo de 1782.

46 AGN-A, XIII-34-3-1. Notas de salida de 1782, nota 3.254 del 29 de noviembre de 1782.

47 AGN-A, XIII-34-3-1. Notas de salida de 1782, nota 3.407 del 11 de diciembre de 1782 .

48 AGN-A, XIII-34-3-1. Notas de salida de 1783, nota 46 del 4 de enero de 1783.

49 Diego A. de la Piedra por su parte, junto a otro Piedra, Juan, fueron aconsejados a Callexas Sanz como reemplazo del segundo consignatario Escurra que dejaba Lima por marzo de 1783. AHPBA, 3-3-6-77, Melchor de Somarriba (Santiago de Chile) a Marcelino Callexas Sanz (Buenos Aires), Santiago de Chile, 2 de mayo de 1783.

50 En el registro de la partida de 165 esclavizados se especifica que "se han introducido desde Montevideo con las guías s 1.491, 1.505 y 1.506, sus fechas 9 y 11 de este mes, y parte [fueron] comprados en esta”. AGN-A, XIII-34-3-1. Notas de salida de 1782, nota 3.133 del 20 de noviembre de 1782. En relación con los otros 51 esclavizados propiedad de Somarriba en la nota correspondiente se dan datos que indican que habían sido comprados en Montevideo en su totalidad: "Todas estas piezas tienen satisfechos a S.M. el derecho de entrada y Alcabala, como acreditan las Guías de la Real Aduana de Montevideo, en donde se han comprado". AGN-A, XIII-34-3-1. Notas de salida de 1782, nota 3.254 del 29 de noviembre de 1782 .

51 Se trata de textiles de calidad media y superior, comprados a Tomás Balanzategui, Domingo Belgrano Pérez, Agustín Casimiro de Aguirre, Felipe Arguibel, Francisco de Segurola y Fernando Orueta: 99 3/4 varas de anafalla; 916 varas de bramante florete; $968 \mathrm{v}$ de bretaña ancha de Francia; 12152 varas de bretaña angosta de Francia; 7068 varas 
Los 165 esclavizados registrados en 1782 partieron hacia Mendoza en carretas de José Obredor a fines de noviembre o inicios del mes siguiente ${ }^{52}$ Los 51 registrados por Somarriba en febrero de 1783, junto con los 34 confiados por Marcelino Callexas Sanz y Ca, y 32 esclavizados registrados por otros individuos 53 fueron expedidos a Mendoza en carretas de Esteban Rodríguez de los Ríos en febrero de 1783 $\sqrt[54]{ }$ Somarriba partió de Buenos Aires en algún momento no muy posterior al 15 de marzo de 1783 (que es la última vez que aparece en las notas de aduana). Si se fue por la posta, es posible que haya llegado a Mendoza antes que las carretas, con lo que podría adelantar la organización del cruce de los Andes ${ }_{55}^{55}$

Los detalles del viaje y negociación de los 34 esclavizados de Marcelino Callexas Sanz y $\mathrm{C}^{\mathrm{a}}$ y sus asociados se conocen por papeles que se conservan de lo que fuera el archivo personal de M. Callexas Sanz, principalmente correspondencia y cuentas.

de coleta aplomada; 272 varas de estopilla clarín; 510 varas de estopilla olán; 3298 varas de estopilla; 108 varas de holandilla; 115 varas de paño de Sedán; 8123.5 varas de puntibí y 420 varas de media zaraza. AGN-A, XIII-34-4-1. Notas de salida de 1783, nota 971 del 15 de marzo de 1783 y nota 1.016 del 17 de marzo de 1783.

52 "remitir para la ciudad de Mendoza en dos tropas de carretas de José Obredor y Ramón Gómez que se hallan prontas a salir". AGN-A, XIII-34-3-1. Notas de salida de 1782, nota 3.133 del 20 de noviembre de 1782 . Además de la parte de esclavizados de Somarriba que llevaba, Obredor transportó en este viaje también 1 esclavizado más registrado por Pedro Albarado y para serle entregado a él mismo en Lima (nota 3.105 de noviembre de 1782), lo que quiere decir que Albarado emprendía el viaje a Lima sin su esclavo. En noviembre de 1782 aparecen unas carretas de Ramón Gómez que salen de Buenos Aires, pero no se registran esclavizados en ellas. Sólo el equipaje de Juan Ignacio Escurra hasta Mendoza en tránsito a Lima y 14 arrobas de yerba por cuenta del mismo Gómez (notas 3.127 y 3.128 del 20 de noviembre de 1783). RegAduAR, base de datos 1779-1783.

53 Joaquín Arana para entregar a Juan Bautista Gárate (dos unidades); Luis Francisco Gardeazabal y Lorenzo Arisnavarreta 30 unidades, sin datos sobre el destinatario, pero confiados a Somarriba para la conducción; Antonio José de Escalada para entregar a Somarriba (una unidad) y Florencio Antonio García 1 unidad (sin datos sobre destinatario). De este modo suman 119 los esclavizados transportados en estas carretas según las notas de aduana. En la liquidación final de los gastos, para calcular la parte de Marcelino Callexas Sanz y Ca se prorratea sobre la base de 117 esclavizados en total. De modo que hay dos esclavizados que o bien no fueron cargados a último momento (pero deberían estar las guías anuladas) o bien fallecieron a poco de comenzarse la travesía.

54 Apenas iniciado el viaje hubo un contratiempo. En un papel anexado a la nota de aduana en el que se registran los esclavizados, Marcelino Callexas Sanz solicita una copia de la guía de salida ya que, tras pasar por la Guardia de Luján, el carretero, "habiendo salido de este paraje por los Arrecifes perdió la cartera en donde llevaba una guía a mi nombre $n^{\circ} 667$ " con lo que pide una copia "para que así en el resto del camino como en la de Mendoza no se me haga perjuicio alguno." AGN-A, XIII-34-4-1. Solicitud. Marcelino Callexas Sanz al Administrador de la Aduana de Buenos Aires, Buenos Aires, 25 de febrero de 1783 (adjuntada a la nota de aduana 667 del 18 de febrero de 1783).

55 En otro hilo de conversación entre Callexas y Somarriba, que no viene al caso detallar, se comenta la próxima partida de una expedición mercantil a Santiago de Chile, comenzando por el trayecto hasta Mendoza. Fulano "pasa a aquella ciudad (Santiago de Chile) con negocio de géneros de Castilla que deberá cargar el 20 del presente y él saldrá por la posta a últimos del que corre a fin de prevenir mulas en Mendoza para no experimentar demora alguna." (AHPBA, 3-1-1-38. Copia de carta. Marcelino Callexas Sanz a Melchor de Somarriba, Buenos Aires, 16 de febrero de 1784). Sobre el entramado de rutas anudadas en el complejo portuario rioplatense hacia el interior americano, los transportes y los transportistas, véase Errecart (2019). 
Aunque en todas las comunicaciones de Somarriba aparece que la operación por 34 esclavizados era por cuenta, costo y riesgo de Marcelino Callexas Sanz y Ca, el negocio era algo más complejo. Aunque la gestión la asume Marcelino Callexas Sanz y Ca , en realidad los esclavizados pertenecían por tercios a dicha compañía, a Manuel Diago y Pedro Álvarez Caballero (asentados en Montevideo y asociados por un tercio ${ }^{56}$ y a Manuel del Molino Torres (por el tercio restante) $[57$

En cuanto al costo de los esclavizados, un copiador de cartas de Callexas Sanz permite saber: "los veintisiete negros y siete negras que entregué a VM en esta para que los vendiese a mi cuenta me tienen de costo principal 250 pesos fuertes [supongo que cada uno] sin incluir la ropa y demás gastos por lo que he de estimar procure dar la más pronta y ventajosa venta según se hallase la Plaza sin reparar en cortedades que lo que VM haga doy por bien hecho" 58

Y en relación con las ventas, se informa desde Lima en agosto de 1783 que fueron hechas:

a unos precios más que regulares según la estación pues parte de ellos se vendieron a cuatrocientos sesenta pesos, algunos a cuatrocientos cuarenta y los demás a cuatrocientos treinta, que nunca lo creí por haber entre ellos muchos Portugueses ... Las ventas se han hecho al contado y fiado, con plazo hasta la salida de navíos para España que esta se podrá demorar cuando mucho cinco o seis meses previniendo que los sujetos son segurísimos 59

Entre medio, la etapa final del viaje forzado de los africanos desde el inicio de su cautiverio hasta el lugar en el que serían explotados, así como el nuevo desarraigo de los afrodescendientes ya esclavizados (los portugueses) se puede recomponer través de correspondencia y de las cuentas de gastos (véase cuadro 5).

El 28 marzo de 1783 las carretas de Esteban Rodríguez de los Ríos llegaron a Mendoza, con lo que tardaron alrededor de un mes desde Buenos Aires ${ }^{60}$ Fallecen dos esclavizados antes de continuarse el viaje desde Mendoza hasta Valparaíso a lomo de mula. Los 32 restantes son embarcados en Valparaíso para Lima el 9 de mayo en el navío Las Caldas. ${ }^{61}$

$56 \mathrm{Al}$ parecer, en algún momento surgieron conflictos entre Diago y Álvarez Caballero, ya que el primero le pide a Marcelino Callexas Sanz que: "se sirva suspender la liquidación de la cuenta de Negros con don Pedro [Álvarez Caballero] entreteniéndole con buenas palabras a fin de evitar cuestiones y para que VM se cerciore mejor de su maldita lengua y modo de proceder le pondré a VM en esa un documento bajo su firma en donde verá lo mucho que tiene recibido y el descubierto en que me hallo y de ese modo sabrá VM a quien ha de entender." AHPBA, 3-1-9-202. Carta. Manuel Diago a Marcelino Callexas Sanz (Buenos Aires), Montevideo, 3 de enero de 1785. Por su parte, Álvarez Caballero, al enterarse por R. García Pérez del pedido de Diago, reclama la liquidación de la cuenta. AHPBA, 3-1-9-202. Carta. Pedro Álvarez Caballero a Marcelino Callexas Sanz y C', Buenos Aires, 8 de enero de 1785.

57 El dato emerge del reparto de las utilidades. AHPBA, 3-1-9-230. Recibo. Manuel Diago y Pedro Álvarez Caballero a favor de Ramón García Pérez y Ca, Buenos Aires, 20 de enero de 1785.

58 AHPBA, 3-1-1-38. Copia de carta. Marcelino Callexas Sanz (Buenos Aires) a Melchor de Somarriba (Santiago de Chile), Buenos Aires, 10 de abril de 1783.

59 AHPBA, 3-1-9-229. Copia certificada por el escribano José García Echaburo de una cuenta (Buenos Aires, 21 de febrero de 1783) y una carta remitida por Melchor de Somarriba a Marcelino Callexas Sanz (Lima, 16 de agosto de 1783), Buenos Aires, 15 de junio de 1784.

60 AHPBA, 3-3-6-75. Copia de la cuenta de venta y líquido producto de 34 piezas de esclavos que condujo Don Melchor de Somarriva, residente y del comercio de esta ciudad, por cuenta, costo y riesgo de los Señores Marcelino Callexas Sanz y Compañía, del comercio de Buenos Aires. Lima, 13 de septiembre de 1784.

61 AHPBA, 3-3-6-77. Carta. Melchor de Somarriba a Marcelino Callexas Sanz (Buenos Aires), Santiago de Chile, 2 de mayo de 1783. Marcelino Callexas Sanz acusa recibo de esta información en junio y da algunas instrucciones y el 10 de septiembre - presumiblemente ante la ausencia de novedades por parte de Somarriba- repite la carta de junio. AHBPA, 


\section{CUADRO 5. BALANCE PARCIAL DE UNA OPERACIÓN DE VENTA DE 34 ESCLAVIZADOS EN LIMA DESDE BS. AS. EN 1783 A CARGO DE MELCHOR SOMARRIBA POR GUENTA, A TERGIOS, DE MARCELINO CALLEXAS SANZ Y C, MANUEL DIAGO AGUADO Y PEDRO ÁLVAREZ CABALLERO Y MANUEL DEL MOLINO TORRES}

\begin{tabular}{|c|c|c|}
\hline Balance & $\begin{array}{l}\text { En contra } \\
\text { (pesos) }\end{array}$ & $\begin{array}{c}\text { A favor } \\
\text { (pesos) }\end{array}$ \\
\hline Venta de los esclavizados & s. d. & 14060.000 \\
\hline Recibidos en Buenos Aires para gastos & s. d. & 290.656 \\
\hline $\begin{array}{l}\text { Descuento por error en el cálculo del } 2 \% \text { de interés } \\
\text { del dinero tomado en Chile. }\end{array}$ & s. d. & 5.750 \\
\hline $\begin{array}{l}\text { Un saco de frijoles con tres arrobas entregado } \\
\text { por Marcelino Callexas Sanz y } C^{\text {a }}\end{array}$ & s. d. & 12.000 \\
\hline $\begin{array}{l}\text { Abonados por Marcelino Callexas Sanz y } \mathrm{C}^{\mathrm{a}} \text { antes } \\
\text { de la partida. }\end{array}$ & $\begin{array}{l}\text { s. d. } \\
\text { s. d. }\end{array}$ & $\begin{array}{r}696.813 \\
15065.219\end{array}$ \\
\hline $\begin{array}{l}\text { Flete de } 34 \text { esclavizados hasta Mendoza, a ocho } \\
\text { pesos cada uno }\end{array}$ & 0 & s. d. \\
\hline Prorrata que corresponde a Marcelino Callexas & & \\
\hline $\begin{array}{l}\text { Sanz y } \mathrm{C}^{\mathrm{a}} \text { del flete de dos carretas hasta Mendoza } \\
\text { para el rancho. }\end{array}$ & 0 & s. d. \\
\hline $\begin{array}{l}\text { Prorrata de } 312 \text { pesos } 2 \text { reales de rancho y varias } \\
\text { menudencias para } 117 \text { esclavizados }\end{array}$ & 0 & s. d. \\
\hline $\begin{array}{l}\text { Prorrata de } 1000 \text { pesos en plata que se llevan } \\
\text { para gastos del camino. }\end{array}$ & 0 & s. d. \\
\hline $\begin{array}{l}\text { Prorrata de } 100 \text { pesos dados a Cayetano Arteta } \\
\text { por el cuidado y asistencia de los esclavizados } \\
\text { hasta Lima. }\end{array}$ & 0 & s. d. \\
\hline $\begin{array}{l}\text { Gastos de comestibles desde Buenos Aires a Mendoza } \\
\text { comprados en el camino }\end{array}$ & 4.781 & s. d. \\
\hline
\end{tabular}

3-1-1-38. Copia de carta. Marcelino Callexas Sanz a Melchor de Somarriba (Santiago de Chile), Buenos Aires, 10 de junio de 1783. AHPBA, 3-1-3-38. Apunte en copiador de cartas. En enero de 1784 Marcelino Callexas Sanz comienza a mostrar cierta angustia por la falta de novedades desde el anuncio de la venta de los esclavizados en agosto de 1783 y comienza a reclamar la cuenta. AHPBA, 3-1-9-229. Carta. Melchor de Somarriba a Marcelino Callexas Sanz, Lima, 16 de agosto de 1783; АнPBA, 3-1-3-38. Copia de carta. Marcelino Callexas Sanz a Melchor de Somarriba (Lima), Buenos Aires, 16 de enero de 1784. En febrero se piden nuevamente las cuentas y la remisión del producto. Ante el silencio de Somarriba, se insiste en abril. AнPвA, 3-1-3-38. Copia de carta. Marcelino Callexas Sanz a Melchor de Somarriba (Lima), Buenos Aires, 16 de abril de 1784. 
Manutención desde la llegada a Mendoza (28 de marzo de 1783) hasta el embarque en Valparaíso (9 de mayo de 1783).

119.875

s. d.

Flete de Mendoza a Valparaíso por 32 esclavizados sobrevivientes. Corresponde a prorrata del conjunto de mulas contratadas para todo el lote bajo cuidado de Somarriba pagar por 19.5 mulas, a 5 pesos 6 reales cada uno.

$112.125 \quad$ s. d

Prorrata que corresponde a Marcelino Callexas Sanz y $\mathrm{C}^{\mathrm{a}}$ de 103 pesos 4 reales por el flete de 18 mulas que condujeron el rancho de Mendoza a Valparaíso.

Derechos de salida de Valparaíso, aforado cada esclavizado en 275 pesos y tasados al $3 \%$.

Intereses de 532 pesos 6 1/4 reales tomados en Chile para pagar gastos y derechos a $2 \%$.

Pasaje de Valparaíso a El Callao, a quince pesos cada uno

Almojarifazgo y Alcabala en Lima, aforada cada esclavizado en 375 pesos, a $11 \%$.

Derecho de Consulado, $1 \%$.

Dados al Alcalde Provincial de Lima por Derecho de 3 pesos 1 real por cada esclavizado

Flete desde El Callao a Lima y lo gastado en manutención hasta la venta.

Pasaje del dependiente que acompañó a los esclavizados desde Valparaíso.

Comisión de M. Somarriba a $6 \%$ sobre el principal.

$\begin{array}{rr}30.000 & \text { s. d. } \\ 264.000 & \text { s. d. } \\ 10.656 & \text { s. d. } \\ 480.000 & \text { s. d. } \\ 1232.000 & \text { s. d. } \\ 112.000 & \text { s. d. } \\ 100.000 & \text { s. d. } \\ 102.563 & \text { s. d. } \\ & \text { s. d. } \\ 15.000 & \text { s. d. } \\ & \\ 843.594 & 15065.219 \\ 4137.406 & 10927.813 \\ \text { s. d. } & 1096.406\end{array}$

Remanente

Remisión

Entregados en Lima a Ramón García Pérez el 9 de septiembre de 1784.

s. d. $\quad 1686.406$

Remanente en contra de Somarriba.

Nota: no están en las cuentas el costo de 34 los esclavizados. Tal vez 8500 pesos. AHPBA, 3-1-1-38. Copia de carta. Marcelino Callexas Sanz (Buenos Aires) a Melchor de Somarriba (Santiago de Chile, Buenos Aires), 10 de abril de 1783. Tampoco se incluyen los derechos pagados en la compra, los gastos de traslado a Buenos Aires desde Montevideo ni el vestuario y la alimentación hasta la partida. El deudor en la liquidación declara falsamente haber despachado como parte de pago 1390 pesos por la vía Potosí-Jujuy-Buenos Aires. Para la reducción al sistema decimal de las cifras: n pesos $=\mathrm{x}$ pesos $+(\mathrm{y}$ reales $/ 8)+(\mathrm{z}$ maravedís $/ 272)$.

Fuentes: AHPBA, 3-1-9-229. Copia certificada por el escribano José García Echaburo de una cuenta (Buenos Aires, 21 de febrero de 1783) y una carta remitida por Melchor de Somarriba a Marcelino Callexas Sanz (Lima, 16 de agosto de 1783), Buenos Aires, 15 de junio de 1784. AHPBA, 3-3-6-78. Copia de la cuenta de venta y líquido producto de 34 piezas de esclavos que condujo Dn Melchor de Somarriba residente yd el comercio de esta Ciudad por cuentam costo y riesgo de los Señores Marcelino Calleja Sanz y Compañía, del comercio de Buenos Aires. Lima, 15 de septiembre de 1784 . 
Algo retuvo a Somarriba en Santiago de Chile o Valparaíso y reaparece en Lima el 16 de agosto de 1783. A través de una carta informa que se concluyó el negocio en Lima antes de que él llegara, por mano de "los amigos Piedra" y en las condiciones ya citadas más arriba. En la cuenta se ve que un religioso compró el mayor lote, 17 unidades, a 430 pesos cada una. Seis fueron comprados por Francisco de la Puente (460 pesos cada unidad), cuatro por José Salazar (460 pesos), otros cuatro por el Conde de San Carlos (430 pesos) y uno por el Marqués de Salinas (430 pesos). Las ventas fueron en parte de contado y en parte a crédito, que se espera cobrar dentro de los seis meses. En diciembre Somarriba anuncia que calcula que en febrero de 1784 tendrá el dinero disponible 62

De los 14060 pesos resultantes solo una pequeña parte llegará a Marcelino Callexas Sanz y $\mathrm{C}^{\mathrm{a}}$.

Los gastos comenzaron antes de la salida. Además de la compra de los esclavizados sobre la que no tengo detalles, entre el flete (272 pesos) y alimentos se gastaron 679 pesos 6 reales. Cayetano Arteta, quien iba a estar a cargo del "cuidado y asistencia de los negros" hasta Lima, recibe 29 pesos $1 / 2$ real 63 Esta cuenta fue saldada antes de comenzar el viaje.

Se debieron comprar más alimentos en viaje y se suman gastos de manutención en Mendoza, nuevos fletes y derechos, así como la comisión de $6 \%$ de Somarriba sobre el principal (843 pesos 4\% reales). Quedaron 10631 pesos 31/4 reales de utilidades brutas, sobre las que hubo que descontar nuevos gastos, relacionados con la llegada del caudal a Buenos Aires y luego parte a Montevideo.

Somarriba anuncia que remitió 1390 pesos por la vía de Potosí a Jujuy y de allí a Buenos Aires, pero luego se supo que no fue así, originándose un impago que no pude saber si se cubrió. ${ }^{64}$ El remanente, 9451 pesos 3 1⁄4 reales fueron recibidos en Lima por Ramón García Pérez el 9 de septiembre de 178466

Todavía había que hacer llegar esos pesos a Buenos Aires y después las partes de los montevideanos a la otra banda del río. La única información que tengo para estimar el remanente final procede de la parte recibida por Manuel Diago y Pedro Álvarez Caballero. Se contentan, al menos en el discurso formal de un recibo, con los 2905 pesos 6 reales que les tocaron en efectivo,

62 AHPBA, 3-3-6-77. Carta. Melchor de Somarriba a Marcelino Callexas Sanz (Buenos Aires), Lima, 26 de diciembre de 1783 .

$63 \mathrm{Al}$ parecer, C. Arteta no consideró necesario registrar su equipaje en la Aduana, ya que no hay ninguna nota suya.

64 En junio de 1784 Marcelino Callexas Sanz recurre en Lima a Silvestre de Amenábar para que reclame a M. de Somarriba la formación de las cuentas de la operación y la entrega del producto. En agosto Amenábar informa desde Lima que Somarriba le dijo que "un día de estos formará la cuenta de venta y gastos” y que "entregará el saldo líquido [...] con descuento de algo más de mil pesos que dice tener dada orden a Potosí para que pase a esa [Buenos Aires].” AHPBA, 3-3-6-90. Carta. Silvestre de Amenábar a Marcelino Callexas Sanz y Co. Lima, 16 de agosto de 1784. Prudentemente desconfiado, Marcelino Callexas Sanz mueve su red de relaciones para conocer el paradero de esos pesos que llegarían por la vía de Potosí. Desde Jujuy Manuel de la Quintana se contacta con José del Ribero (Potosí) quien a su vez le informó que "carecía de la menor noticia sobre el particular". AHPBA, 3-3-6-93. Carta. Manuel de la Quintana a Marcelino Callexas Sanz. Jujuy, 24 de diciembre de 1784.

65 En mayo de 1783 García Pérez había partido hacia Santiago de Chile para vender efectos de Castilla por cuenta de una asociación entre Marcelino Callexas Sanz y Ca y un comerciante porteño. Mientras estaba en Santiago de Chile parece que dio un salto hasta Lima solo para cobrar este dinero, ya que es lo único que le veo hacer allí.

66 Por mano de Pedro Bernales por libranza de Domingo Piedra. AHPBA, 3-3-6-75. Copia de la cuenta de venta y líquido producto de 34 piezas de esclavos que condujo don Melchor de Somarriva, residente y del comercio de esta ciudad, por cuenta, costo y riesgo de los señores Marcelino Callexas Sanz y Compañía, del comercio de Buenos Aires. Lima, 13 de septiembre de 1784 . 
descontados los últimos gastos, más la posible recuperación de su parte de los 1390 pesos que Somarriba retiene ${ }^{67}$ De modo que el neto a repartir entre las tres partes debe haber rondado los 8715 peso ${ }^{68}$ y a poco más de dos años de comenzada la operación.

Si por la copia de carta de Callexas Sanz citada antes el costo inicial de los esclavizados fue de 8500 pesos, se suman los derechos correspondientes y se recuerdan los gastos previos a la salida que no se consideran en la liquidación final, la conclusión es que el negocio tiene que haber ido a pérdida y que la única expectativa de compensar las cuentas y obtener alguna ganancia se redujeron a la improbable recuperación de los 1390 pesos que Somarriba no termina de entregar. El apoderado en Lima de Marcelino Callexas Sanz y C ${ }^{a}$ para este asunto en $1785{ }^{69}$ aconseja discretamente, y con buenos argumentos, dejar el asunto librado a la voluntad de pagar de Somarriba. 70 El hilo de información se corta allí.

\section{Conclusión}

Como se expuso al comienzo, este es un trabajo sin pretensiones, que busca poner a disposición informaciones que pueden ser de interés para otras investigaciones al tiempo que observa algunos detalles de la circulación entre Río de la Plata y el Bajo Perú a través de Mendoza-San Juan y Santiago de Chile-Valparaíso. Se trató de realizar la descripción más densa que permiten las fuentes consultadas y relacionar el negocio seguido con otros y el conjunto de transacciones en el que estuvo inserto.

La comparación entre las cifras de esclavizados desembarcados en el periodo 1779-1783 y los expedidos desde Buenos Aires muestra desfasajes que merecen más explicaciones que las que se pueden dar en este trabajo con las informaciones manejadas. Solo considero prudente utilizar los datos para aportar elementos relacionados con una hipótesis sobre el comercio ilegal.

67 AHPBA, 3-3-9-230. Recibo. Manuel Diago y Pedro Álvarez Caballero a favor de Ramón García Pérez y Ci , Buenos Aires, 20 de enero de 1785.

68 Si la asociación era a utilidades y pérdidas, que es lo que parece ser el caso.

${ }^{69}$ Lo que indica que el negocio seguía generando gastos, esta vez relacionados con el establecimiento de poderes, correspondencia, gastos del apoderado en las acciones de recupero de la deuda y sus eventuales comisiones.

70 A comienzos de 1785 el dinero no había llegado a Buenos Aires y los asociados tienen datos sobre que la remisión nunca existió. Ello mueve a Ramón García Pérez a escribir a Lima para reconvenir el pago, y de la respuesta obtenida se confirma la deuda y se observa que el recurso a la justicia es el último a emplear. Esa respuesta llega bajo la forma de una carta formal y un billete sin firma. La primera, de tono bastante neutro, dice que Somarriba "manifestó serle imposible en la actualidad verificarlo [el pago], dando razones que no será cordura fiar a la pluma. En esta inteligencia y considerando que nada se avanzaría con presentarse contra él para ejecutarlo a su cumplimiento, lográndose solamente perder el dinero e imposibilitar al sujeto de poderlo satisfacer en lo sucesivo, he determinado suspender por ahora toda otra inteligencia...". En el billete sin firma, que llegó dentro de la carta pero que no podría ser usado ante la justicia por su forma, se aclara "lo que no sería cordura fiar a la pluma": "Habiendo estrechado con viveza al deudor de los 1390 pesos dice que fue arbitrio el suponer la orden dada a Potosí para el envío de ellos a esa ciudad, con objeto de libertarse por entonces de las instantáneas reconversiones de VM, que lo tenían sofocado. Que se halla en absoluta imposibilidad de pagar por ahora (que así creo) y que de presentarse contra él sólo se conseguiría desconceptuarlo enteramente con todos e inhabilitarlo para las ropas que le tienen ofrecido sus parientes luego de que llegue el primer navío de registro de España, para viajar al Cuzco a expenderlas.” АнPвA, 3-1-9-203. Carta y billete. Silvestre de Amenábar a Ramón García Pérez y $\mathrm{C}^{\circ}$ (Buenos Aires), Lima, 16 de marzo de 1785. 
Ante la variedad y cantidades de bienes comercializados por el circuito legal desde Buenos Aires, las ponderaciones sobre la magnitud del comercio ilegal en la bibliografía, las modalidades concretas a través de las cuales se efectuaban los tratos ilícitos ${ }^{71}$ y la capacidad de fiscalización y represión de las autoridades se puede pensar que las cantidades de bienes registrados hacia el interior americano pueden ser en buena parte resultado del blanqueamiento de bienes introducidos desde ultramar o Brasil por los diversos caminos de la ilegalidad en el complejo portuario rioplatense. Los datos presentados en este texto mostrarían que la hipótesis no se aplica al comercio de esclavizados, que sería uno de los más atractivos para lograr la legalización de un bien tan visible. Los esclavizados revelados por las notas de aduana representan $76.35 \%$ de los desembarcados legalmente entre 1779 y 1783 . Aunque en el residuo haya que contabilizar muertes, se suponga que todos los registrados en la base de datos hayan sido bozales (no lo eran) y esté contenida la venta de esclavizados en Buenos Aires que la base de datos no registra, así como tampoco una parte de los vendidos en Montevideo para su consumo y su traspaís, aún quedarían muchos esclavizados del comercio legal sin conocerse su destino físico como para que además el comercio registrado hacia el interior americano contuviese el blanqueamiento de los ingresados de modo ilegal ${ }^{72}$ Sin duda, existe un problema de fuentes por resolver.

En relación con la distribución espacial de los 5415 esclavizados registrados, Buenos Aires y Montevideo son los grandes mercados, no solo para la circulación extrarregional, sino -y lógicamente- para el mercado regional. Al no existir cifras de la circulación de esclavizados a nivel regional para periodos posteriores es difícil ponderar las cantidades y decir en qué punto nos encontramos del camino que en el discurso de los hacendados rioplatenses cuaja en 1794 y recoge A. Borucki para proponer que por entonces mostraban preferencia por la mano de obra esclavizada. Al menos, ya para comienzos de los años 1780 se estaría perfilando la tendencia. La región Río de la Plata (15.81\%), aunque muy lejos, es el segundo mercado consumidor tras la ruta del Oeste (65.72\%). Lo que nos lleva a la circulación extrarregional.

En las rutas de Centro, Norte y Paraguay, los interesados en la posesión de esclavizados deben proveerse en Buenos Aires de modo mayoritario, en persona o a través de terceros. Al parecer, en los puntos intermedios y extremos de esas rutas no habría un mercado de esclavizados lo suficientemente dinámico como para atraer operaciones por cuenta y riesgo de los tratantes. Además, las cifras confirman en este caso específico la atracción de la ruta del Oeste para el comercio practicado desde Río de la Plata. Hacia allí se orientan los que por la envergadura de sus acciones y los riesgos incurridos pueden ser calificados de empresarios (al menos en la primera definición de Cantillon) ${ }^{73}$ por ser el destino de las mayores cantidades de esclavizados por cuenta de los declarantes para la venta en el mercado receptor.

\footnotetext{
${ }^{71}$ Los bienes provenientes del comercio directo o del fraude fiscal, una vez desembarcados e introducidos sigilosamente en los almacenes en la práctica era imposible diferenciarlos de los del circuito legal. A menos que se tratase de bienes de circulación prohibida. Véase Jumar (1988).

72 Para que la hipótesis se sostenga, el mercado regional se tendría que haber provisto en Buenos Aires y Montevideo de un número mayor de esclavizados que los contenidos en el $24.61 \%$ de los desembarcados en el periodo que no se ve aparecer en los registros de salida de la aduana porteña (1 745 personas). Solo así, parte de los registrados podrían ser esclavizados introducidos de modo ilegal que se blanquean al redistribuirse.

73 "un agente de dirección de la producción y del comercio que asume solo los riesgos vinculados a las imposiciones del mercado y a las fluctuaciones de los precios”. Tounés (2004, p. 4. Trad. del francés F. Jumar). Formaini (2001); Echánove (2015).
} 
En relación con esos empresarios que, por gusto o por fuerza, corren grandes riesgos, 74 las cuentas del negocio emprendido por Marcelino Callexas Sanz y C $\mathrm{C}^{\mathrm{a}}$ y sus asociados muestran que las cosas podían salir mal con facilidad. Un accidente (el fallecimiento de dos esclavizados en el camino) y un eslabón roto en la cadena (el incumplimiento de Somarriba), por un lado, reducían el ingreso bruto esperable y, por otro lado, aumentaban los gastos (los relacionados con las reconvenciones e intentos de recuperación de la deuda que incluyen el traslado a Lima de uno de los asociados y la designación de un apoderado al efecto). Al parecer, el negocio terminó en pérdida. Aún si se hubiese contado con los 250 pesos resultantes de no haberse sufrido contratiempos, se abre la duda sobre la rentabilidad del negocio, considerando que no se incluyen en las cuentas el costo de los esclavizados, los derechos iniciales pagados, el vestuario, el traslado desde Montevideo y el mantenimiento hasta la salida de Buenos Aires. Si como sostenía Somarriba en una de sus cartas los precios obtenidos en Lima se pueden considerar buenos en la coyuntura, este negocio puntual genera interrogantes sobre las ganancias esperables de intentar operar de modo directo en el mercado limeño desde Buenos Aires y torna más racionales las conductas de la mayoría de quienes actúan en dirección del Oeste (y no sólo en relación con la trata esclavista) que se contentan con llegar con sus acciones hasta Mendoza-San Juan para que allí tomen el relevo actores llegados de tras los Andes. Al parecer, en el periodo observado, los prudentes y hasta timoratos, en conjunto tal vez tuviesen más éxito que los osados aunque a cuentagotas y son quienes dinamizan y dan regularidad a los circuitos.75

Todo esto confirma las observaciones de José Sovarzo (2019) quien ve en Mendoza-San Juan la garganta del comercio entre el Atlántico y el Pacífico, y que la ruta es preferida -en cuanto a acciones emprendidas desde el complejo portuario rioplatense- a la vía marítima por el Cabo de Hornos. Surge la pregunta en torno a desde cuándo es posible observar el fenómeno y su explicación. En cuanto a esto último, y mirando desde Santiago de Chile, Sovarzo (2019) propone que en el último cuarto del siglo XviII:

a muchos comerciantes chilenos les era conveniente el "goteo" de mercadería que se producía vía Mendoza, más no la llegada en masa de mercaderías al puerto de Valparaíso. A partir de ello pienso que las redes comerciales tendidas por lo menos durante un siglo entre comerciantes chilenos y mendocino-rioplatenses dificultaron por algunos años el éxito de la ruta del Cabo de Hornos abierta legalmente a partir de 1740. A veces no sólo pagar menos influye a la hora de comprar mercaderías en los distintos mercados. Ciertas costumbres, beneficios, redes y contraprestaciones varias no son menores para los comerciantes a la hora de elegir a quién y a cuánto comprar (Sovarzo, 2019, p. 370).

$74 \mathrm{Al}$ tiempo de estarse concretando la operación de esclavizados detallada, Callexas Sanz se dirige en los siguientes términos a un interlocutor peninsular, amigo de infancia: "No puedo menos que decirte que eres un cobarde pues no has determinado en esta guerra mandar nada para ésta sabiendo que adonde está el riesgo está la ganancia. Yo alabaré el corazón de don José de Castro Sande porque teniendo un principal corto se expuso a mandar sus pacotillas muy buenas y en unas que me mandó a mí de unos 500 pesos ha venido a sacar 1300 y si no hubiera traído las maulas [mercaderías invendibles] que trajo se hubieran vendido con mayor estimación.” AHPBA, 3-1-1-38. Copia de Carta. Marcelino Callexas Sanz a Antonio Mathé (La Coruña), Buenos Aires, 15 de octubre de 1782.

75 Son numerosas las investigaciones sobre los comerciantes que operaban en Buenos Aires, y en menor medida en Montevideo. Los estados del arte más densos al respecto, hasta inicios de la década de 2010, se encuentran en Schlez (2014) y Caula (2014), que además tienen la virtud de analizar en algunos casos los mismos títulos desde diferentes marcos ideológicos, aunque convergen en la inserción del problema dentro del paradigma estatal-colonial. Para otra mirada, véanse Jumar y Kraselsky (2007) y Jumar (1990, 2001, 2003, 2006, 2007, 2011, 2016b). 
En un periodo mayor y en cuanto al lugar de la ruta del Oeste en la historia de la circulación extrarregional rioplatense desde la invasión europea, casi toda la bibliografía sobre circuitos que observa Río de la Plata producida desde los años 1970-1980 inscribe sus explicaciones generales en el modelo propuesto por Carlos Sempat Assadourian (1972), lo que deriva en dar la primacía a las rutas de Centro y Norte (Jumar, 2014).

Para detectar antecedentes de lo observado para el periodo 1779-1783 en relación con la ruta del Oeste y que pone en entredicho el modelo general, se puede recurrir a las operaciones de la South Sea Company en Buenos Aires entre 1715 y 1738. De los 57 navíos que se presentaron ante las autoridades de Buenos Aires fletados por la compañía esclavista británica, cinco no transportaban esclavizados. En los 52 restantes, 14973 esclavizados sobrevivieron la travesía y fueron desembarcados legalmente en Buenos Aires ${ }^{76}$ De ese total, y gracias al trabajo de Elena Studer ([1958]1984), se disponen informaciones sobre la primera venta de 10811 esclavizados $(72.20 \%)$ y de ellos, hay datos sobre la introducción de 7806 (52.13\% del total y, curiosa coincidencia, $72.20 \%$ de los con datos sobre la primera venta). De esta última cifra, fueron enviados hacia el Oeste 6092 esclavizados (78.04\%; $40.69 \%$ del total desembarcado; $56.35 \%$ de los con datos sobre la primera venta). 77 De modo que es posible plantear la idea de que ya en la primera mitad del siglo XviII la ruta del Oeste tiene la misma relevancia para Río de la Plata que tenía a finales del mismo.

Se puede proponer que la trata esclavista puede ser uno de los pilares de la articulación de la ruta del Oeste desde el complejo portuario rioplatense. El otro pilar sin duda es la yerba mate.78 Hasta que en 1740 se habilita la navegación en dirección del Pacífico sur por dentro del circuito legal español, la ruta del Oeste rioplatense era el único medio posible de enlazar el Atlántico y el Pacífico en el hemisferio sur para el comercio legal. Desde 1740 en adelante, los hábitos adquiridos y, sobre todo, la disminución de riesgos ante la fragilidad de ambos tipos de bienes, habrían hecho que se mantuviera la preferencia por esa ruta, antes que la marítima que hasta 1698 utilizaba el endemoniado Estrecho de Magallanes y desde ese año, y gracias a los contrabandistas franceses, doblaba el más previsible - pero no menos peligroso- Cabo de Hornos. Junto a los esclavizados y la yerba mate, otros bienes emprenden el camino de Mendoza-San Juan y Santiago de ChileValparaíso y Puertos del Pacífico hacia el Norte hasta convertirse en la más significativa para el comercio que opera en o desde Río de la Plata.

Si esto fuese así, desde periodos tempranos se abren preguntas interesantes sobre el origen y mecanismos de la circulación por los que llegan al complejo portuario rioplatense buena parte de los metales preciosos embarcados hacia el Atlántico por cuenta del comercio.

\section{LISTA DE REFERENCIAS}

Assadourian, C. S. (1972). Integración y desintegración regional en el espacio colonial. Un enfoque histórico. Revista de Estudios Urbano Regionales, 2(4), 11-23.

76 Jumar (2010, pp. 239-245).

77 Jumar (2010, chapitre V, annexe 2, pp. 533-566).

78 El estudio de la circulación de la yerba mate merece un trabajo en particular. Algunos datos que permiten observar la orientación hacia el Pacífico de la economía paraguaya con la mediación rioplatense en Jumar (2019b, pp. 311-312). De las 496586.62 arrobas de yerba que se distribuyen desde Buenos Aires entre 1779 y $1783,85.75 \%$ se destinan a la circulación extrarregional; 390636.26 arrobas se dirigen hacia el Oeste $(78.66 \%$ del total, $91.74 \%$ de la circulación extrarregional). RegAduAR, base de datos 1779-1783. 
Bentancur, A. A. (1985). Don Cipriano de Melo, señor de fronteras (vol. 2). Montevideo: Arca.

Borucki, A. (2011). The Slave Trade to the Río de la Plata, 1777-1812: Trans-Imperial Networks and Atlantic Warfare. Colonial Latin American Review, 20(1), 81-107. DoI: 10.1080/10609164 2011.552550

Borucki, A. (2015). 250 años de tráfico de esclavos hacia Río de la Plata: De la fundación de Buenos Aires a los "colonos" africanos de Montevideo, 1585-1835. 6tas. Jornadas Uruguayas de Historia Económica. Montevideo: Asociación Uruguaya de Historia Económica.

Borucki, A. (2016). Notas sobre el tráfico de esclavos al Río de la Plata durante el siglo XviII. Revista Latino-americana de Estudos Avançados, 1(1), 7-28.

Borucki, A. (2017). De compañeros de barco a camaradas de armas: Identidades negras en el Río de la Plata. Buenos Aires: Prometeo Libros.

Camarda, M. (2015). La región Río de la Plata y el comercio ultramarino durante las últimas décadas del siglo XVIII: actores, circulación comercial y mercancías (Tesis de doctorado). Universidad Nacional de La Plata, Argentina.

Caula, E. (2014). Mercaderes de mar y tierra: Negocios, familia y poder de los vascos en el Río de la Plata. Rosario: Facultad de Humanidades y Artes Ediciones.

Crespi, L. (2000). El comercio de esclavos en el Río de la Plata. Apuntes para su estudio. Cuadernos de historia. Serie Economía y Sociedad, (3), 237-252.

Crespi, L. (2010). En busca de un enclave esclavista. La expedición colonizadora a las islas de Fernando Poo y Annobon, en el Golfo de Guinea (1778-1782). Revista Digital Estudios Históricos, 2(4), 1-34.

Damiani, R. (2018). Pedro Duval, trayectoria de un comerciante de esclavos en el Río de la Plata, 17951805 (Tesis de licenciatura). Universidad Nacional de Tres de Febrero, Argentina.

Echánove, I. (2015). El empresario y el contexto económico (Tesis de licenciatura). Universidad Pontificia Comillas, Madrid.

Errecart, M. C. (2019). Comercio y comunicación en el Río de La Plata. La articulación de los mercados regionales en el periodo virreinal rioplatense. Los caminos, los transportes y los transportistas. El Taller de la Historia, 11(11), 230-268.

Formaini, R. L. (2001). The engine of capitalist process: Entrepreneurs in economic theory. Economic anCantillond Financial Review, 4, 2-11.

Jumar, F. (1988). Les "rioplatenses" et le Río de la Plata. Les modalités du commerce rioplatense et les groupes locaux, 1680-1777. En Mémoire du Diplôme d'Études Approfondies (p. 168). París: École des Hautes Études en Sciences Sociales.

Jumar, F. (1990). L'élite Porteña et les modalités du commerce au xvıIIe siècle. En Documents de recherche: Vol. 12. CREDAL (pp. 15-32). París: Institut des Hautes Études de l'Amérique Latine.

Jumar, F. (2007). Comercio, comerciantes y revolución en el Río de la Plata. Siglo XviII-principios del siglo xix. En M. Guerra, C. Mazzeo, y D. Rouillon (eds.), Historias compartidas. Economía, sociedad y poder, siglos XVI-XX (pp. 307-343). Lima: Pontificia Universidad Católica del Perú Instituto Riva-Agüero.

Jumar, F. (2010). Le commerce atlantique au Rio de la Plata, 1680-1778 (Tesis de doctorado). Universidad Nacional de La Plata, Argentina.

Jumar, F. (2014). El espacio colonial peruano en la historiografía sobre circulación mercantil. História Ecônomica \&̊ História de Empresas, 17(2), 475-534. 
Jumar, F. (2016a). Abogados y negocios. Las relaciones mercantiles entre Río de la Plata y el Alto Perú reveladas por la correspondencia entre Francisco de Prieto y Pulido y Juan Antonio Ruiz Tagle, 1768-1798. V Congreso Latinoamericano de Historia Económica. Presentado en São Paulo. São Paulo: Asociaciones Nacionales Latinoamericanas de Historia Económica/Universidade de São Paulo.

Jumar, F. (2016b). "Buscar la vida" en Río de la Plata: Marcelino Callexas Sanz, 1757-1820 (Dossier). Illes $i$ imperis, 18, 44-76.

Jumar, F. (2016c). El comercio ultramarino por el complejo portuario rioplatense y la economía regional, 1714-1778. Magallánica: Revista de Historia Moderna, 3(5), 166-259.

Jumar, F. (2016d). Las "reformas borbónicas" en la formación de la historiografía argentina. Historia Caribe, 11(29), 113-154.

Jumar, F. (2018). El mundo hispánico durante el Antiguo Régimen desde los circuitos mercantiles y el espacio económico rioplatense. Historia Crítica, 70, 23-44. DoI: 10.7440/histcrit70.2018.02

Jumar, F. (2019a). Apuntes para una modelización: La región Río de la Plata durante su pertenencia a la monarquía hispánica y en el proceso de formación del Estado-nación argentino. El Taller de la Historia, 11(11), 5-27.

Jumar, F. (2019b). Hay para todos. La circulación intra y extrarregional de Río de la Plata observada desde la Aduana de Buenos Aires, 1779-1783. El Taller de la Historia, 11(11), 294-344.

Jumar, F., y Paredes, I. (2008). El comercio intrarregional en el complejo portuario rioplatense: El contrabando visto a través de los comisos, 1693-1777. América Latina en la Historia Económica, 15(1), 31-96. DOI: 10.18232/alhe.v15i1.388

Kraselsky, J. (2019). Privilegios y favores en el Río de la Plata a fines del siglo XviII. La 'centralización corporativa' como interpretación posible del sistema de poder. El Taller de la Historia, 11(11), 28-65.

Prado, F. (2012). A carreira transimperial de don Manuel Cipriano de Melo no rio da Prata do século XVIII. Topoi (Rio de Janeiro), 13(25), 168-174. DoI: 10.1590/2237-101X013025010

Rebagliati, L. (2014). ¿Una esclavitud benigna? La historiografía sobre la naturaleza de la esclavitud rioplatense. Andes. Antropología e Historia, 25(1), 1-29.

Sandrín, M. E. (2016). La demanda de bienes y servicios para la corona y la navegación ultramarina en el complejo portuario rioplatense y la dinamización de la economía regional, 1680-1810 (Tesis de doctorado). Universidad Nacional de La Plata, Argentina.

Scelle, G. (1906). La traite négrière aux Indes de Castille. Contrats et traités d'assiento (vols. 1-2). París: Librairie de la Société du Recueil J. B. Siret \& du Journal du Palais.

Schlez, M. M. (2014). Los circuitos comerciales tardo-coloniales. El caso de un comerciante monopolista: Diego de Agüero (1770-1820) (Tesis de doctorado). Universidad de Buenos Aires, Argentina.

Sovarzo, J. (2019). La garganta del comercio suramericano. Las relaciones comerciales terrestres entre la región Río de La Plata y los mercados del Pacífico Suramericano a fines de la dominación hispánica en América. El Taller de la Historia, 11(11), 345-384.

Studer, E. F. S. (1984). La trata de negros en el Río de la Plata durante el siglo XVIII. Buenos Aires: Libros de Hispanoamérica.

Tounés, A. (2004). L'entrepreneur: l'odyssée d'un concept. Cahiers de recherche de l'Agence Universitaire de la francophonie, 3(73), 1-22. 
Vaccani, M. E. (2019). Los servidores reales en Río de la Plata. Las acciones de Francisco Ximénez de Mesa en la Real Aduana de Buenos Aires. Una continuidad histórica en la dinámica institucional de la Monarquí, 1774-1788 (Tesis de maestría). Universidad Nacional de Tres de Febrero, Argentina. 